Supporting Information for the Paper Entitled:

\title{
Crystalline Hydrogen-Bonding Networks and Mixed-Metal Framework Materials Enabled by an Electronically Differentiated Heteroditopic Isocyanide/Carboxylate Linker Group
}

\author{
Krista P. Balto, Milan Gembicky, Arnold. L. Rheingold and Joshua S. Figueroa* \\ Department of Chemistry and Biochemistry, University of California, San Diego, 9500 Gilman Drive, \\ Mail Code 0358, La Jolla, California, 92093-0358, United States \\ Email:jsfig@ucsd.edu.
}

\section{Contents}

S1. ${ }^{1} \mathrm{H}$ NMR and IR Spectroscopic Data for TIB ${ }^{\mathrm{Mes} 2}$ and Precursors ............................................ S-2

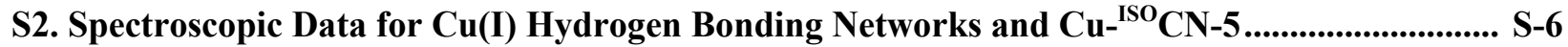

S3. Results of ICP-MS Analysis on Digested Cu/Zn- ${ }^{\text {ISO }} \mathrm{CN}-5$...................................................... S-12

S4. Details of TGA and Gas Sorption Analysis .................................................................................. S-13

S5. Details of X-ray Single-Crystal and Powder Diffraction Studies ................................................ S-17

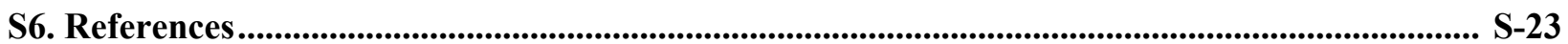


S1. ${ }^{1} \mathrm{H}$ NMR and IR Spectroscopic Data for TIB $^{\mathrm{Mes} 2} \mathrm{H}$ and Precursors

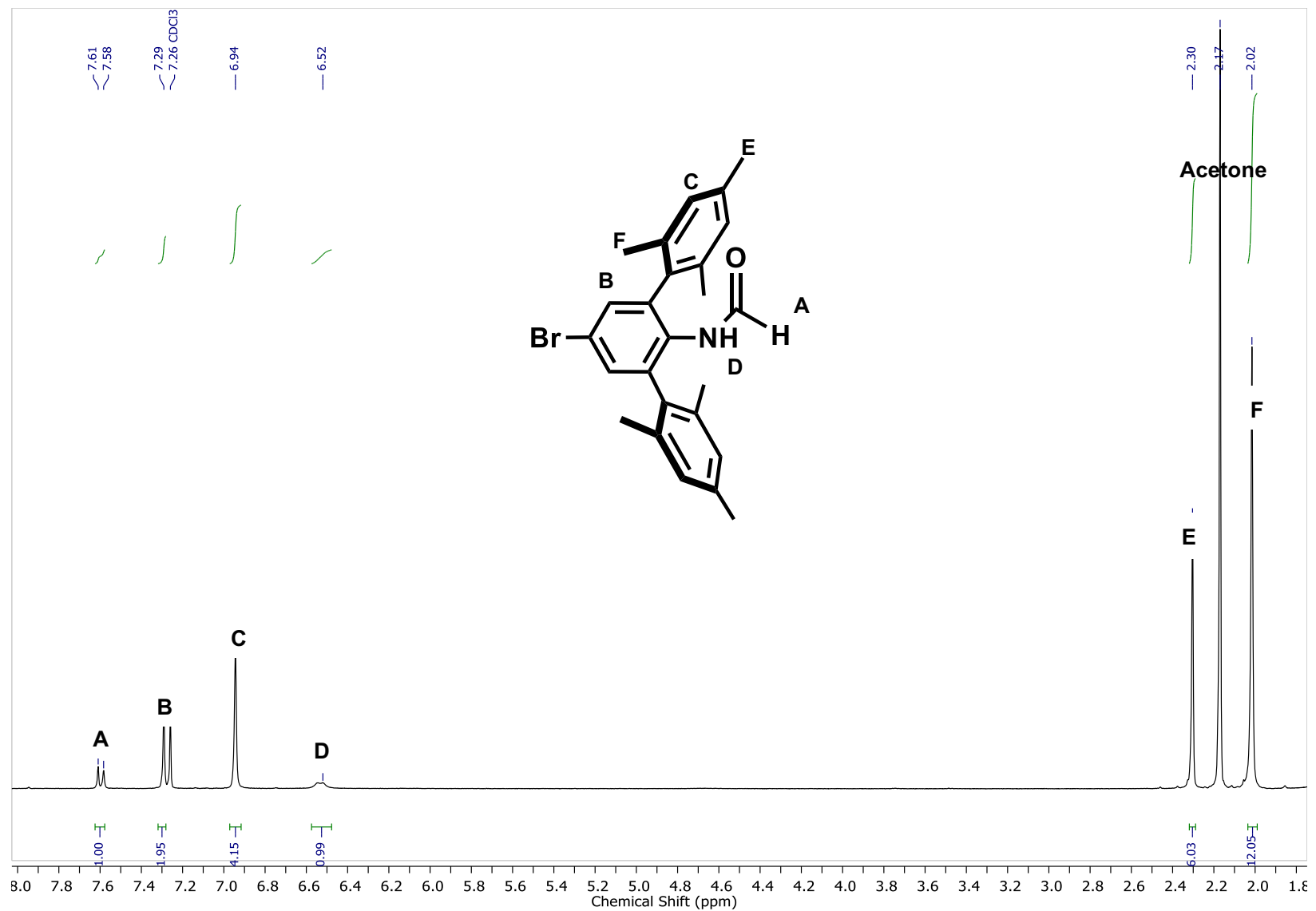

Figure S1.1. ${ }^{1} \mathrm{H}$ NMR spectrum $\left(\mathrm{CDCl}_{3}, 300 \mathrm{MHz}, 20{ }^{\circ} \mathrm{C}\right)$ of $\mathrm{HC}(\mathrm{O}) \mathrm{NH}\left(p\right.$-BrAr $\left.{ }^{\mathrm{Mes} 2}\right)$.

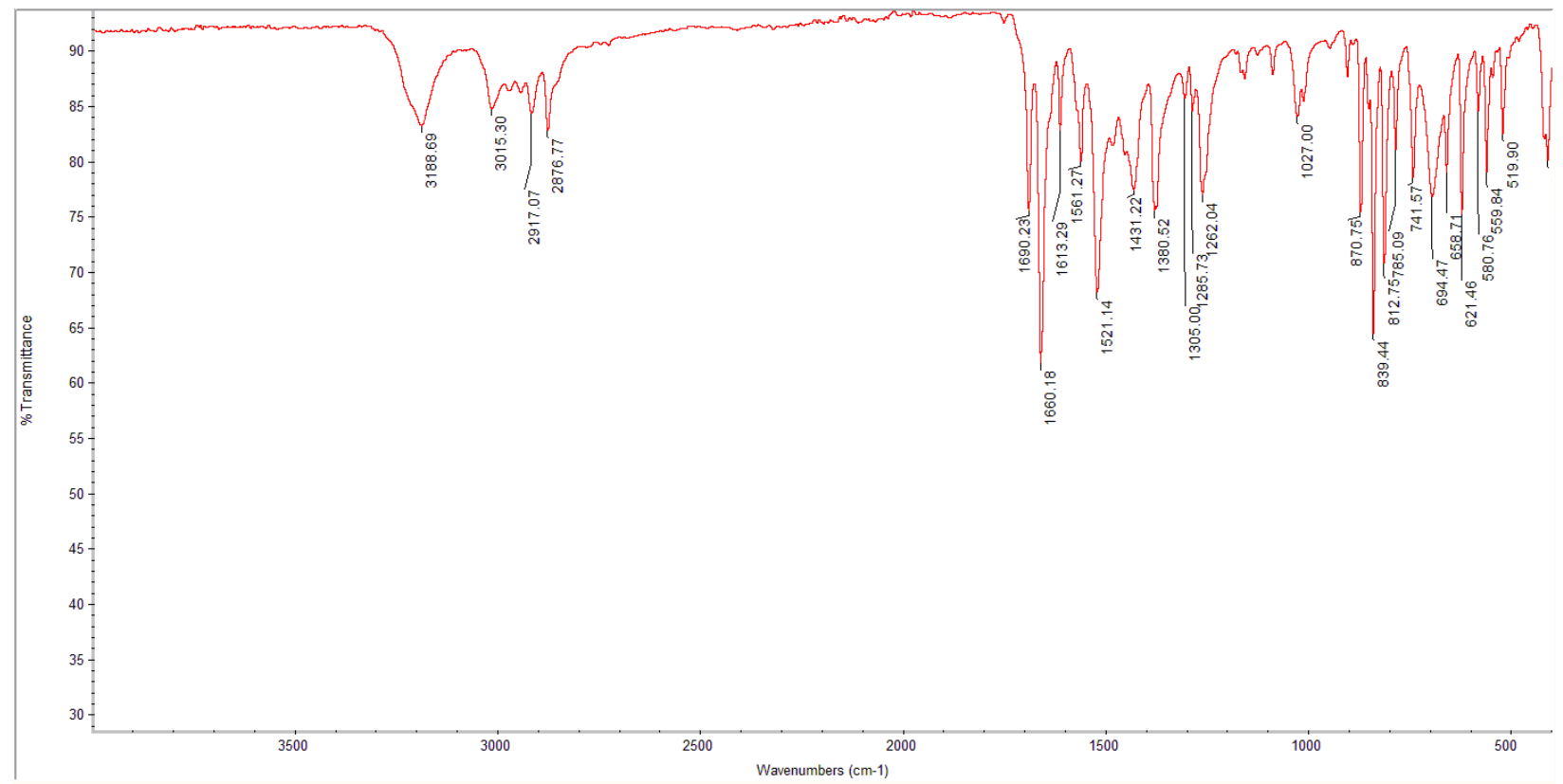

Figure S1.2. ATR-IR spectrum $\left(20^{\circ} \mathrm{C}\right)$ of $\mathrm{HC}(\mathrm{O}) \mathrm{NH}\left(p-\mathrm{BrAr}^{\mathrm{Mes} 2}\right)$. 


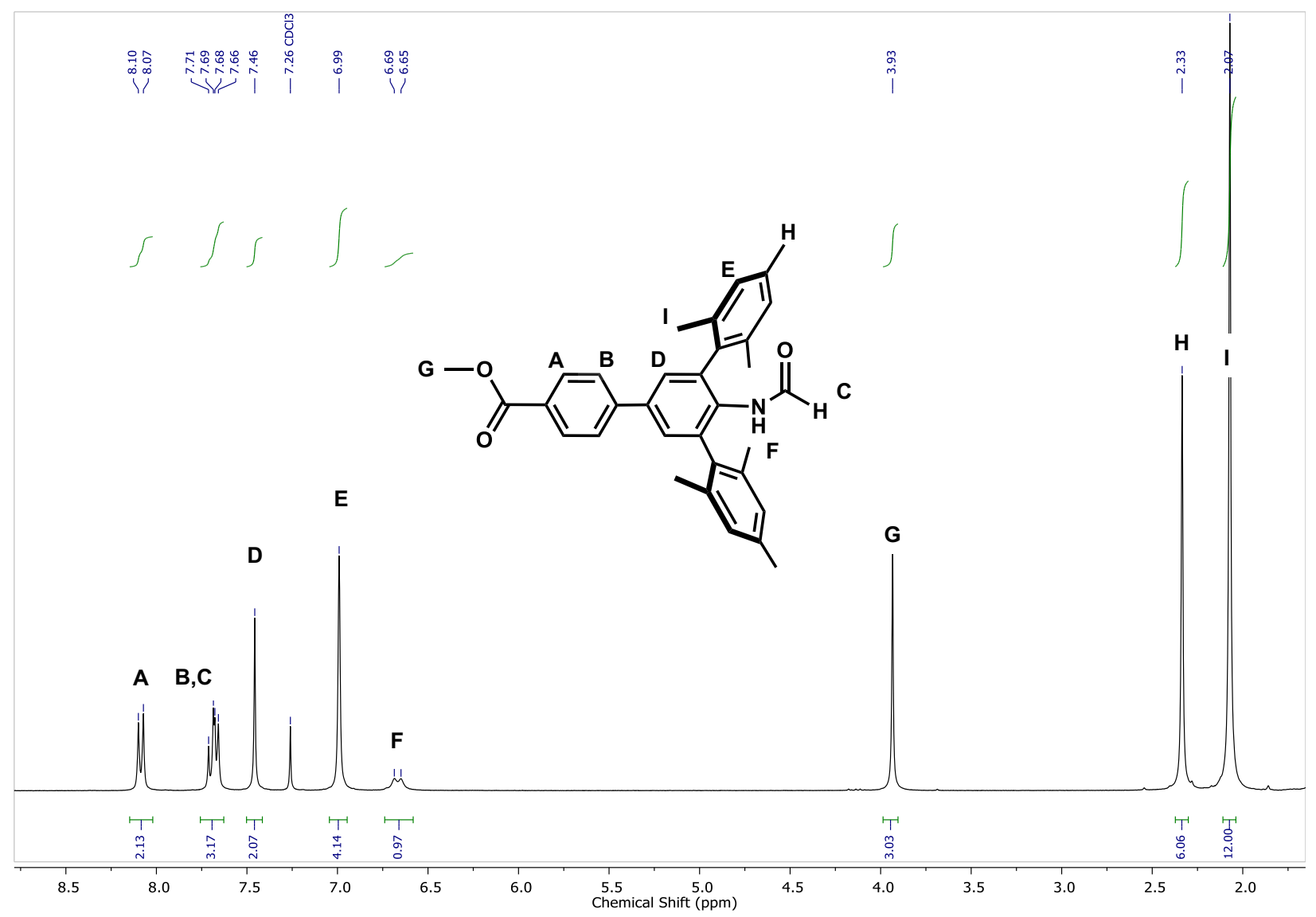

Figure S1.3. ${ }^{1} \mathrm{H}$ NMR spectrum $\left(\mathrm{CDCl}_{3}, 300 \mathrm{MHz}, 20{ }^{\circ} \mathrm{C}\right)$ of $1-\mathrm{HC}(\mathrm{O}) \mathrm{N}(\mathrm{H}) \mathrm{Ar}^{\mathrm{Mes} 2}-4-\mathrm{C}_{6} \mathrm{H}_{4} \mathrm{CO}_{2} \mathrm{CH}_{3}$.

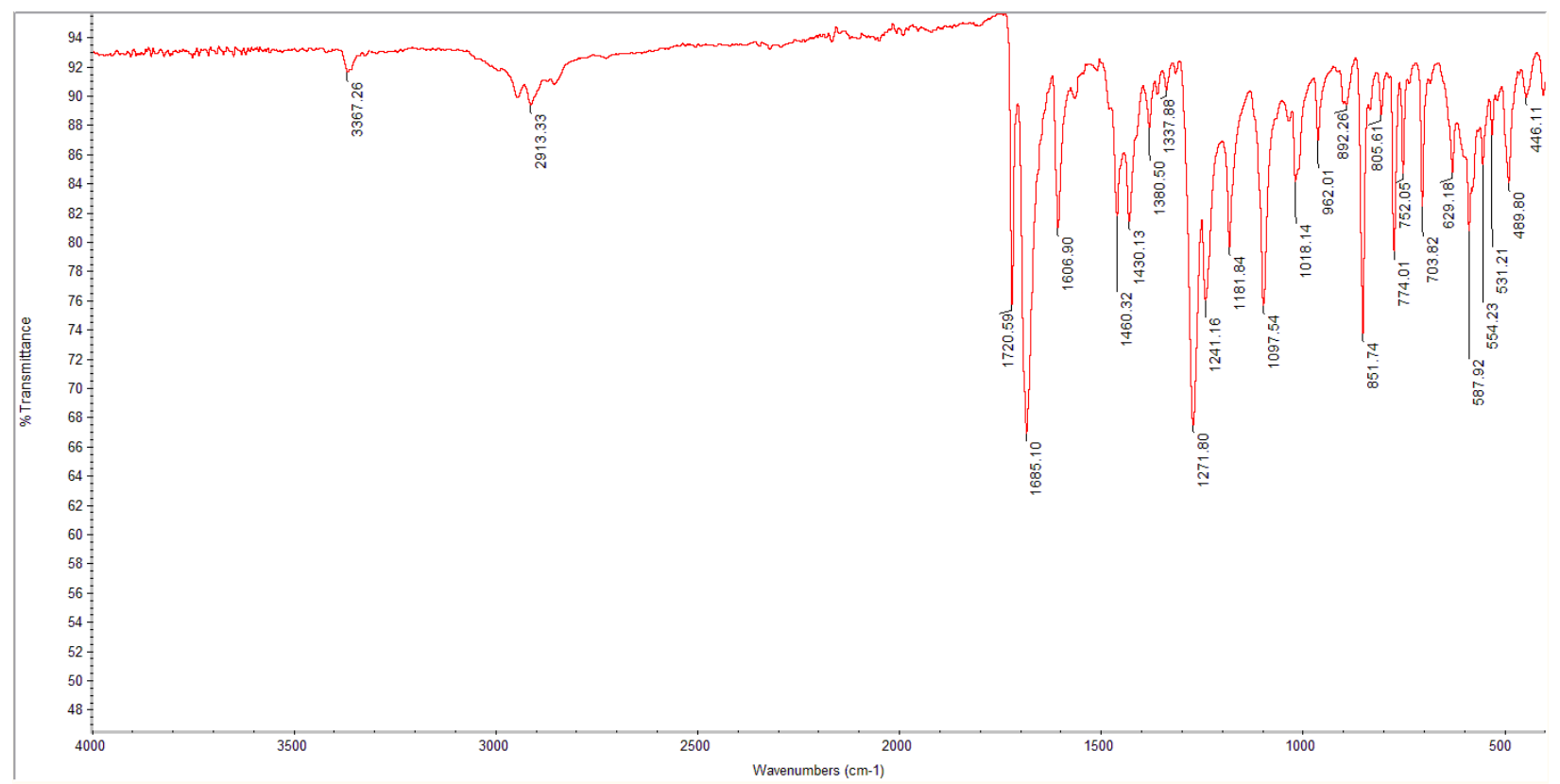

Figure S1.4. ATR-IR spectrum $\left(20^{\circ} \mathrm{C}\right)$ of $1-\mathrm{HC}(\mathrm{O}) \mathrm{N}(\mathrm{H}) \mathrm{Ar}^{\mathrm{Mes} 2}-4-\mathrm{C}_{6} \mathrm{H}_{4} \mathrm{CO}_{2} \mathrm{CH}_{3}$. 


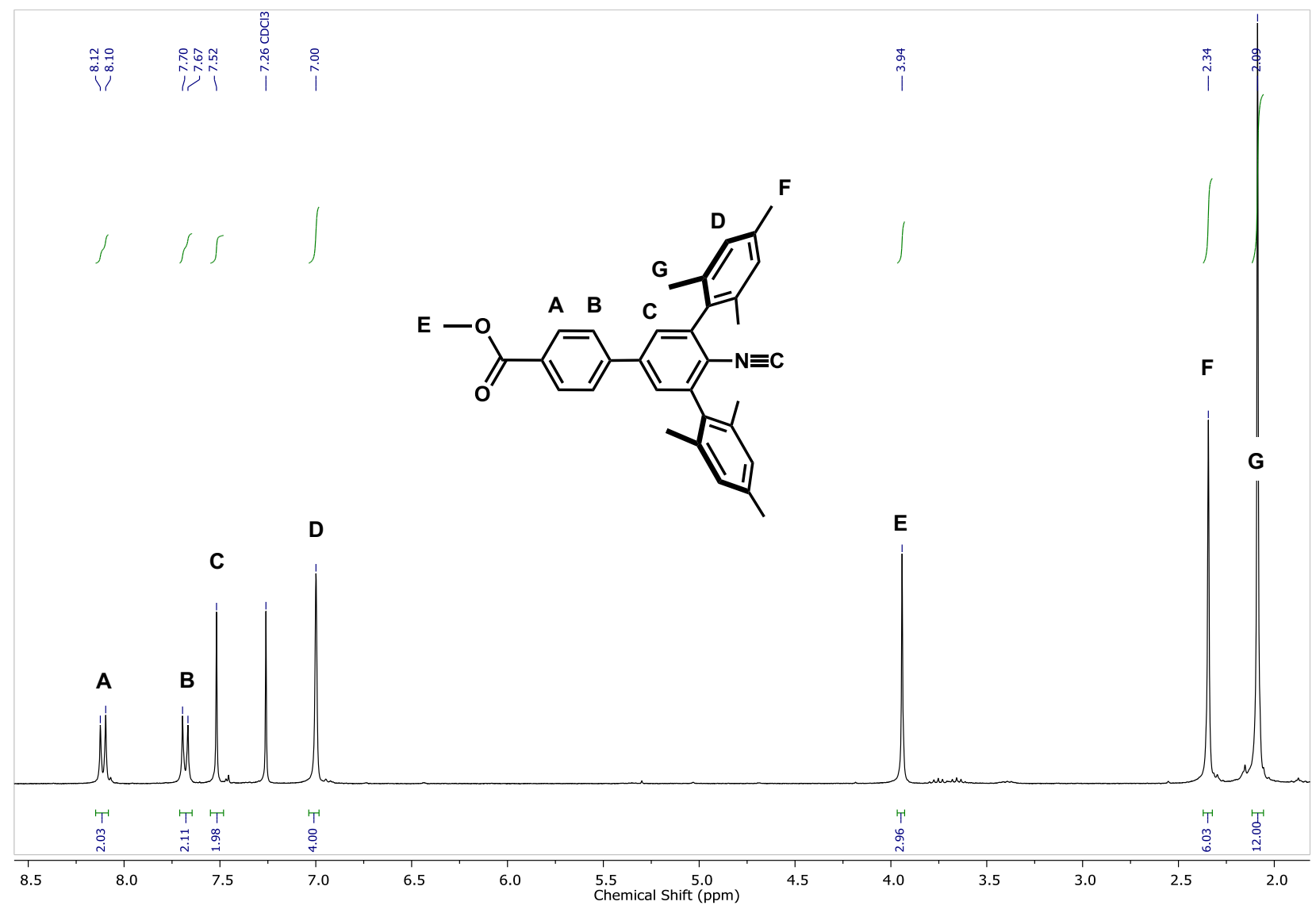

Figure S1.5. ${ }^{1} \mathrm{H}$ NMR spectrum $\left(\mathrm{CDCl}_{3}, 300 \mathrm{MHz}, 20{ }^{\circ} \mathrm{C}\right)$ of $1,4-\left(\mathrm{CNAr}{ }^{\mathrm{Mes} 2}\right) \mathrm{C}_{6} \mathrm{H}_{4} \mathrm{CO}_{2} \mathrm{CH}_{3}$.

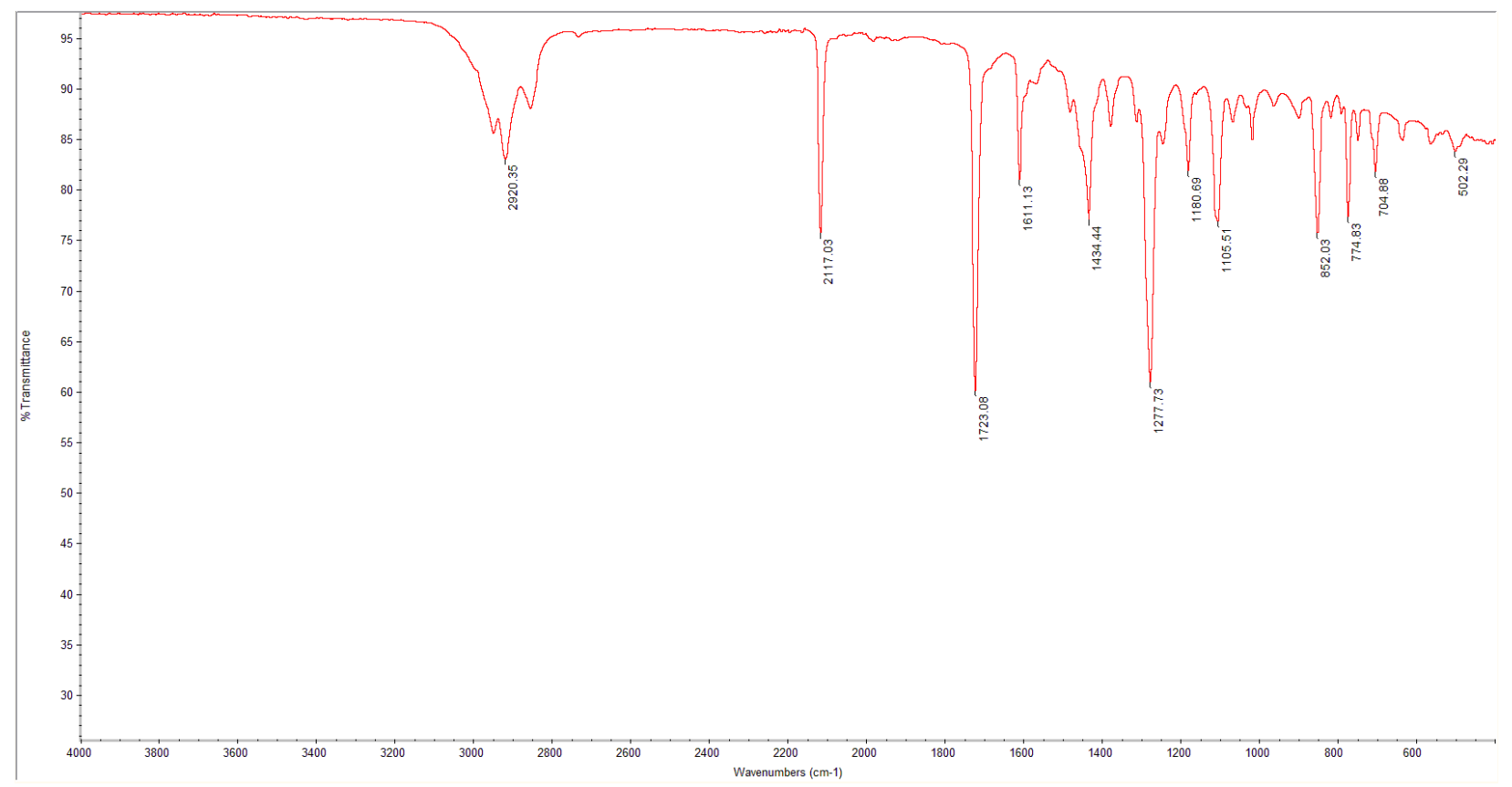

Figure S1.6. ATR-IR spectrum $\left(20^{\circ} \mathrm{C}\right)$ of $1,4-\left(\mathrm{CNAr}^{\mathrm{Mes} 2}\right) \mathrm{C}_{6} \mathrm{H}_{4} \mathrm{CO}_{2} \mathrm{CH}_{3}$. 


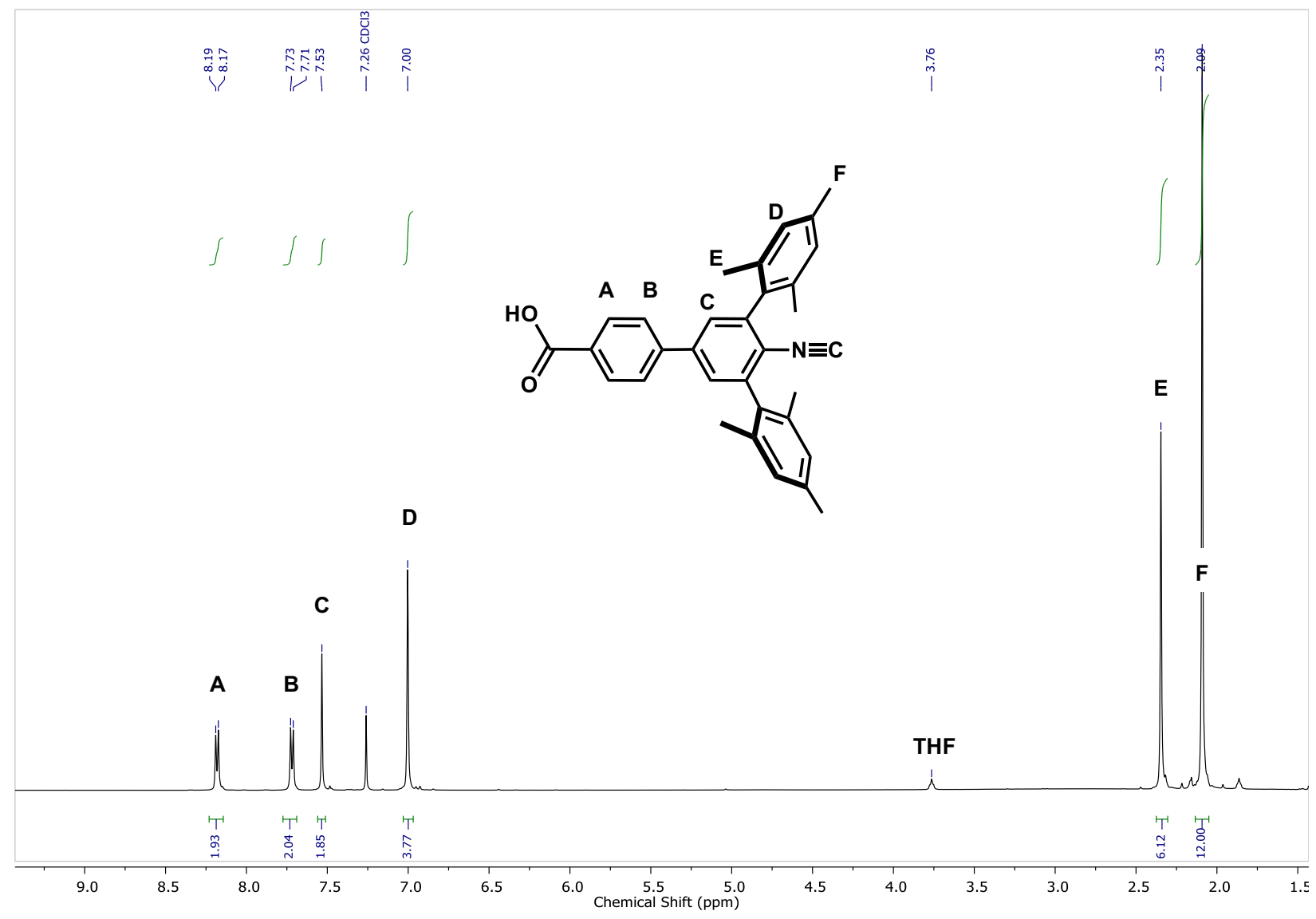

Figure S1.7. ${ }^{1} \mathrm{H}$ NMR spectrum $\left(\mathrm{CDCl}_{3}, 500 \mathrm{MHz}, 20{ }^{\circ} \mathrm{C}\right)$ of $1,4-\left(\mathrm{CNAr}^{\mathrm{Mes} 2}\right) \mathrm{C}_{6} \mathrm{H}_{4} \mathrm{CO}_{2} \mathrm{H}\left(\mathrm{TIB}^{\mathrm{Mes} 2} \mathrm{H}\right)$. 


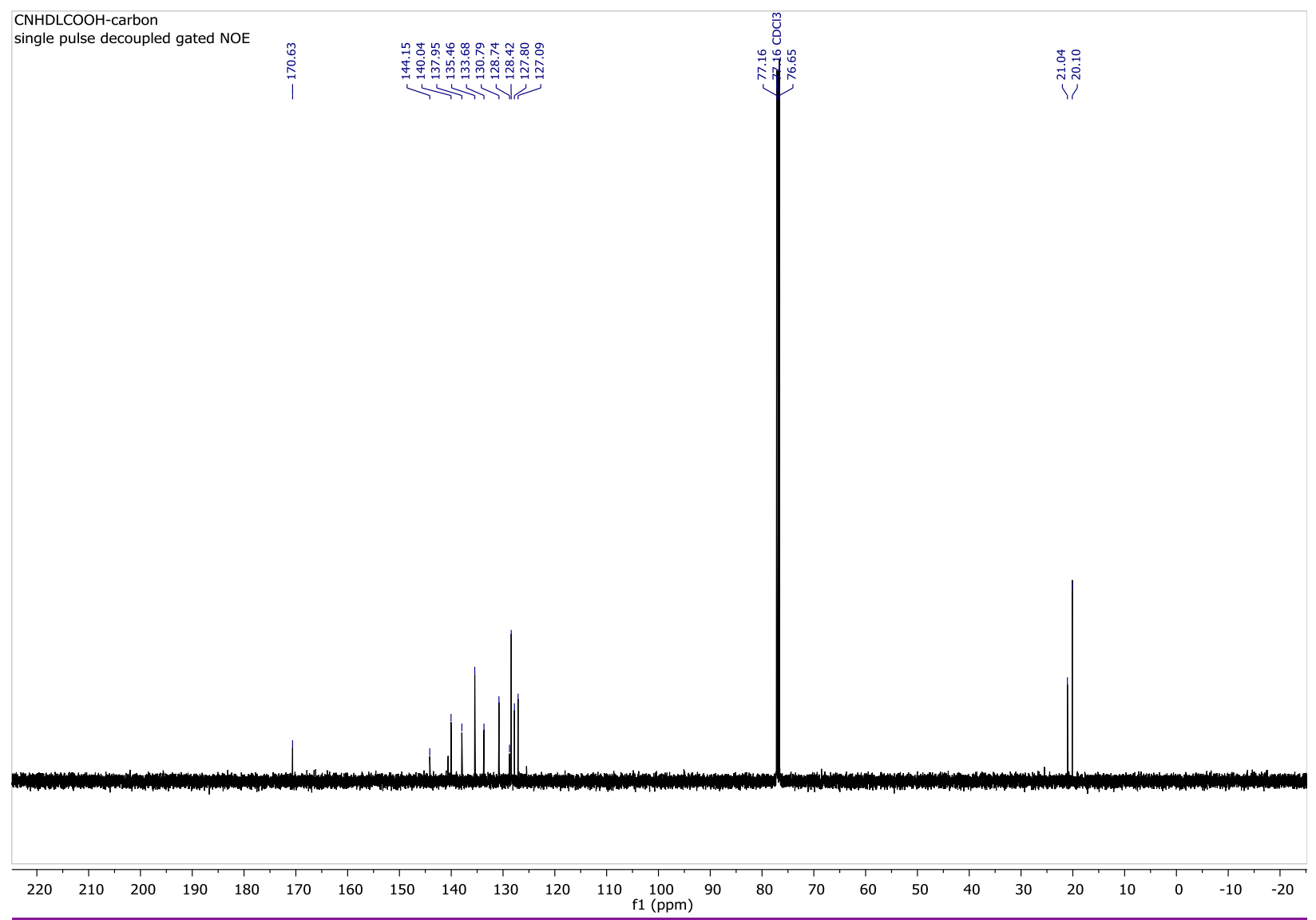

Figure S1.8. ${ }^{13} \mathrm{C}$ NMR spectrum $\left(\mathrm{CDCl}_{3}, 500 \mathrm{MHz}, 20{ }^{\circ} \mathrm{C}\right)$ of $1,4-\left(\mathrm{CNAr}^{\mathrm{Mes} 2}\right) \mathrm{C}_{6} \mathrm{H}_{4} \mathrm{CO}_{2} \mathrm{H}\left(\mathrm{TIB}^{\mathrm{Mes} 2} \mathrm{H}\right)$.

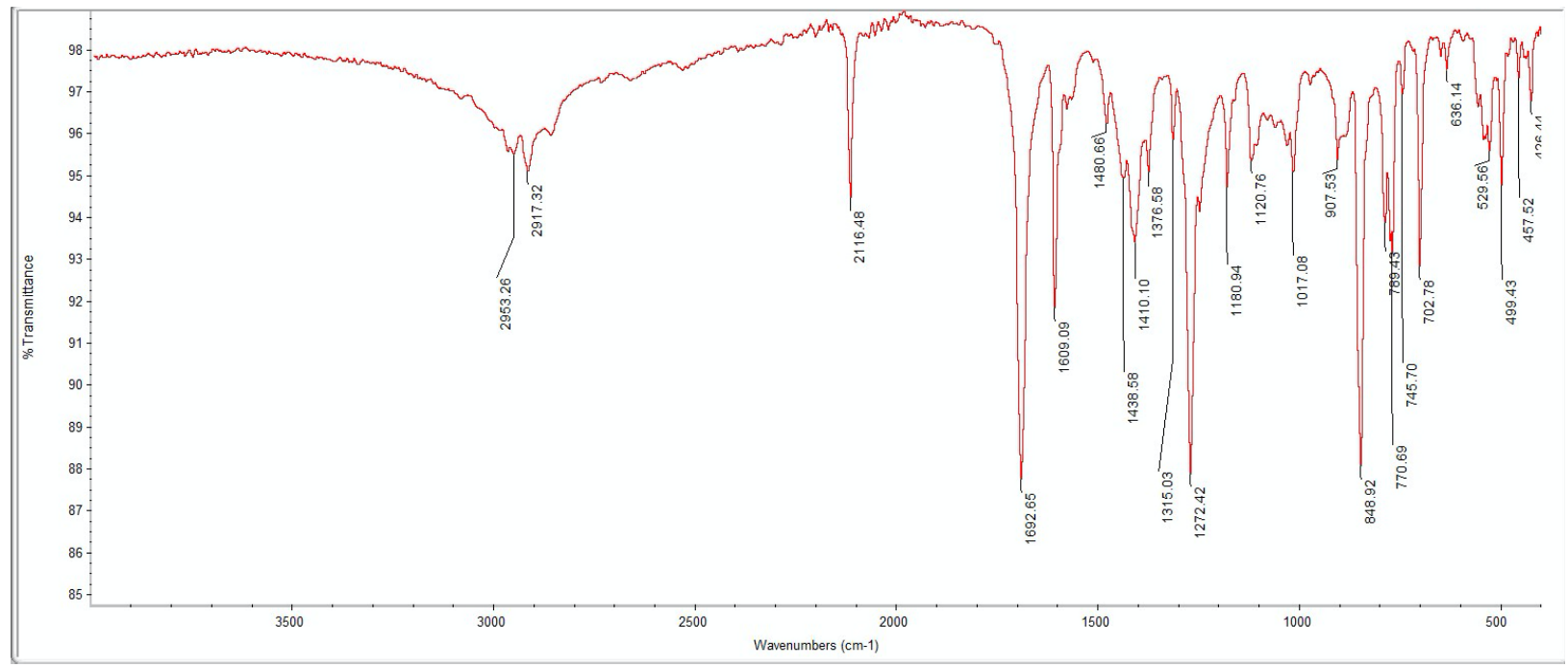

Figure S1.9. ATR-IR spectrum $\left(20{ }^{\circ} \mathrm{C}\right)$ of $1,4-\left(\mathrm{CNAr}^{\mathrm{Mes} 2}\right) \mathrm{C}_{6} \mathrm{H}_{4} \mathrm{CO}_{2} \mathrm{H}\left(\mathrm{TIB}^{\mathrm{Mes} 2} \mathrm{H}\right)$. 
S2. Spectroscopic Data for $\mathrm{Cu}(\mathrm{I}) \mathrm{Hydrogen}$ Bonding Networks and $\mathrm{Cu} / \mathrm{Zn}-{ }^{\mathrm{ISO}} \mathrm{CN}-5$.

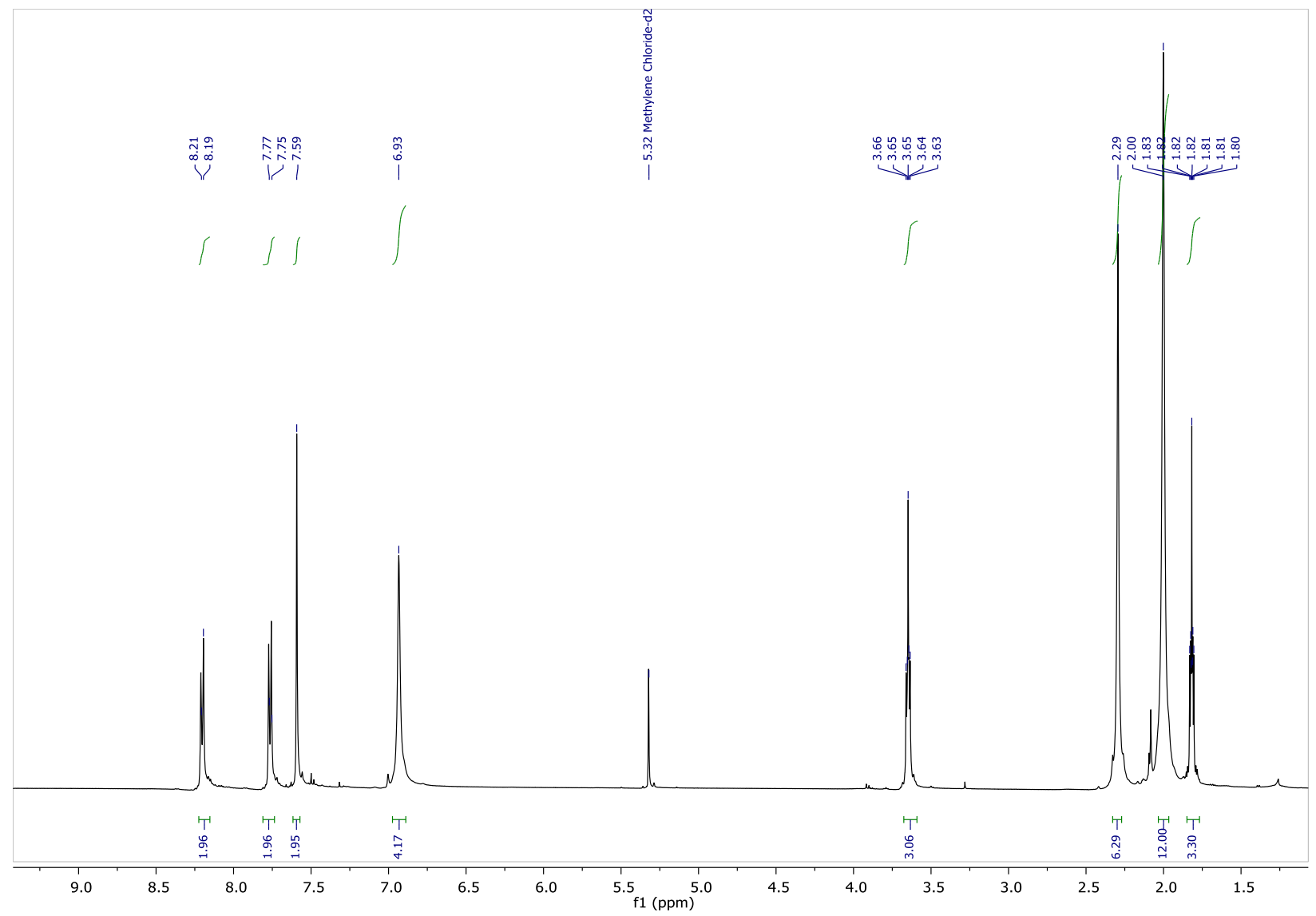

Figure S2.1. ${ }^{1} \mathrm{H}$ NMR Spectrum $\left(500 \mathrm{MHz}, \mathrm{CD}_{2} \mathrm{Cl}_{2}, 20{ }^{\circ} \mathrm{C}\right)$ from reaction of 3.0 equiv $\mathrm{TIB}^{\mathrm{Mes} 2} \mathrm{H}$ and $\left[\mathrm{Cu}(\mathrm{NCMe})_{4}\right] \mathrm{PF}_{6}$. THF present is suggestive of $\left[\mathrm{Cu}(\mathrm{THF})\left(\mathrm{TIB}^{\mathrm{Mes} 2} \mathrm{H}\right)_{3}\right] \mathrm{PF}_{6}$ environment in solution. 


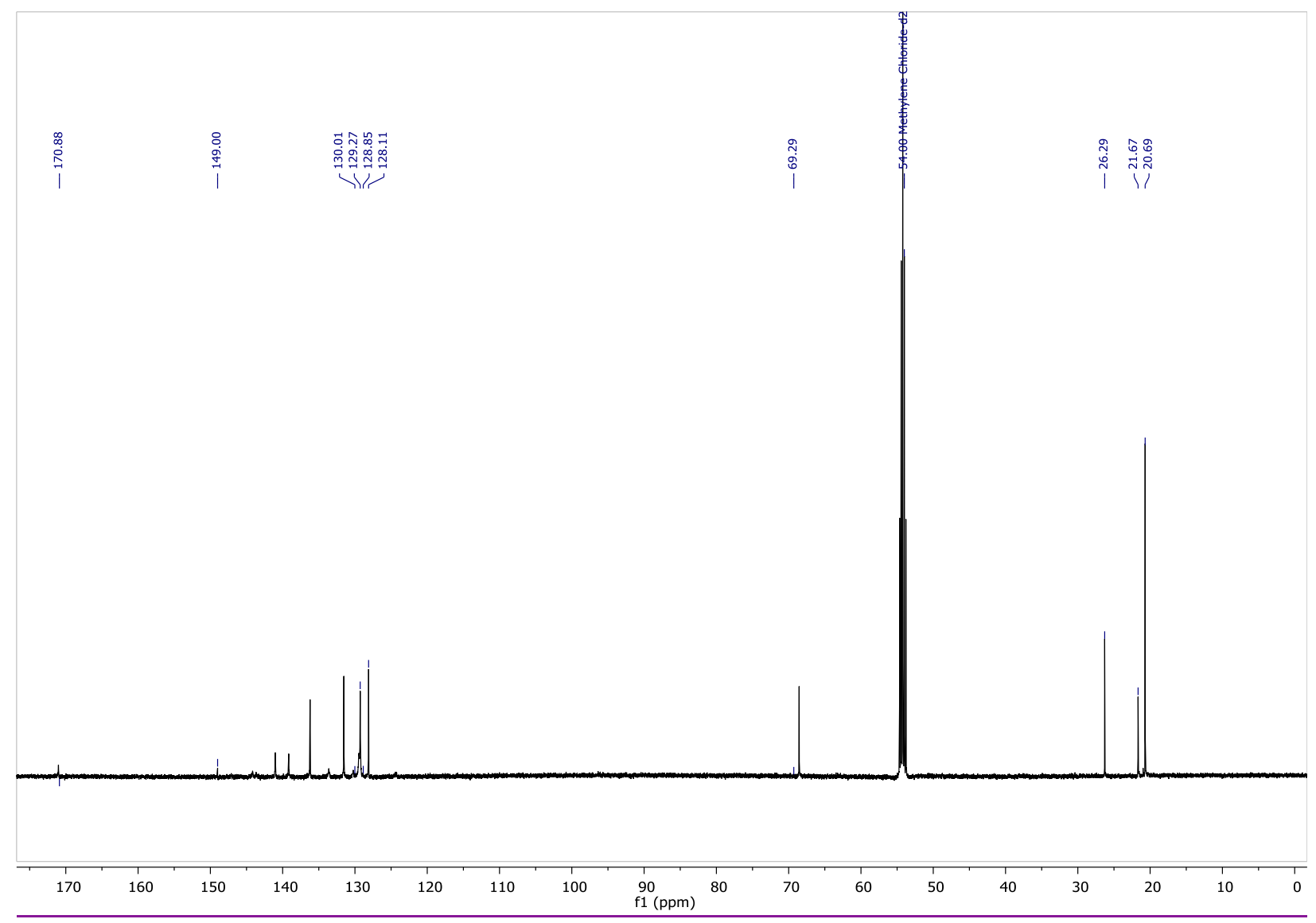

Figure S2.2. ${ }^{13} \mathrm{C}$ NMR Spectrum $\left(500 \mathrm{MHz}, \mathrm{CD}_{2} \mathrm{Cl}_{2}, 20{ }^{\circ} \mathrm{C}\right)$ from reaction of 3.0 equiv $\mathrm{TIB}{ }^{\mathrm{Mes} 2} \mathrm{H}$ and $\left[\mathrm{Cu}(\mathrm{NCMe})_{4}\right] \mathrm{PF}_{6}$. 


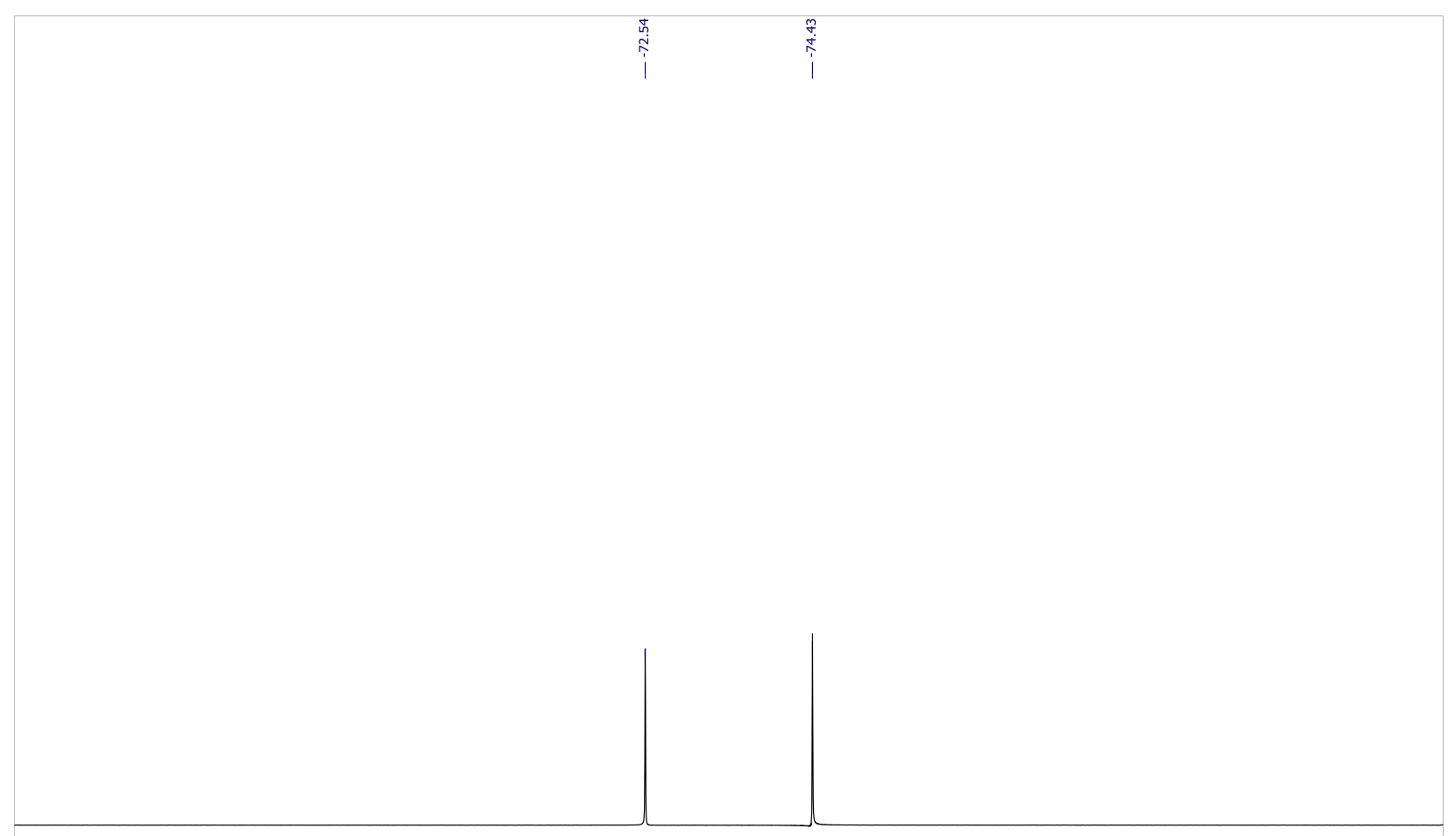

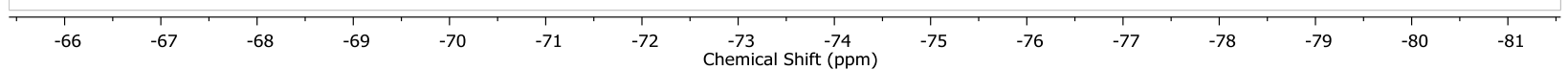

Figure S2.3. ${ }^{19} \mathrm{~F}$ NMR Spectrum $\left(282.3 \mathrm{MHz}, \mathrm{CD}_{2} \mathrm{Cl}_{2}, 20{ }^{\circ} \mathrm{C}\right)$ from reaction of 3.0 equiv $\mathrm{TIB}^{\mathrm{Mes} 2} \mathrm{H}$ and $\left[\mathrm{Cu}(\mathrm{NCMe})_{4}\right] \mathrm{PF}_{6}$.

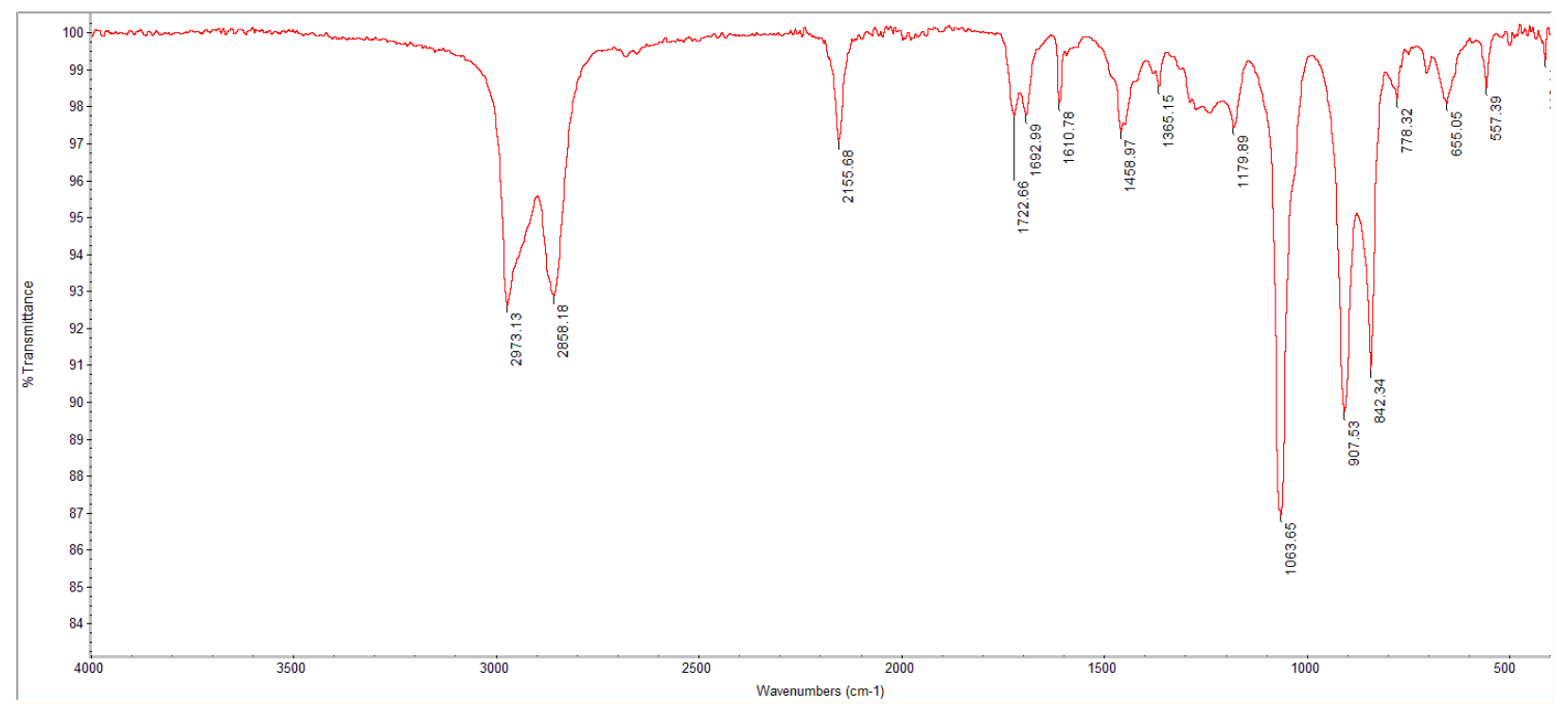

Figure S2.4. Solution IR Spectra of 3.0 equiv $\mathrm{TIB}^{\mathrm{Mes} 2} \mathrm{H}$ and $\left[\mathrm{Cu}(\mathrm{NCMe})_{4}\right] \mathrm{PF}_{6}$ in $\mathrm{THF}$. 


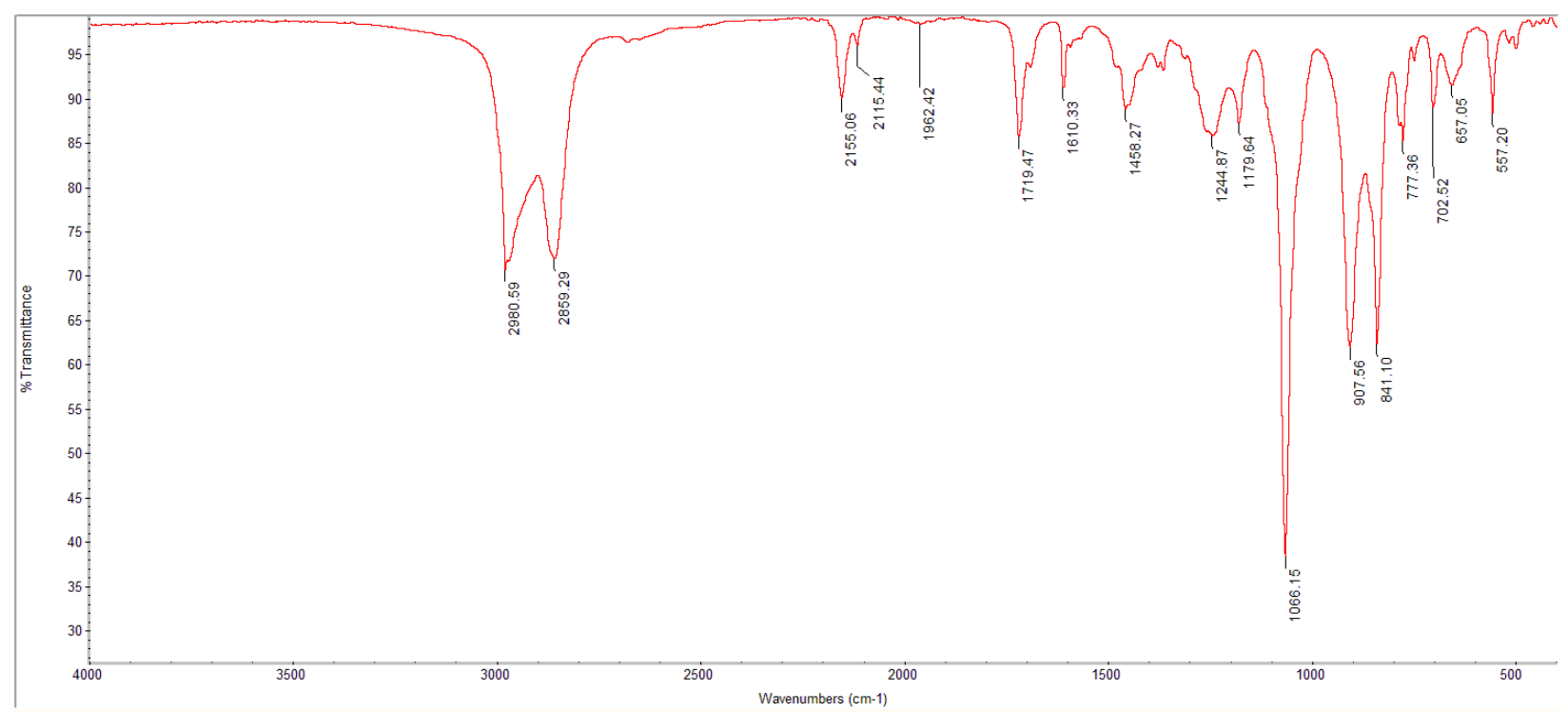

Figure S2.5. Solution IR Spectra of 4.0 equiv $\mathrm{TIB}^{\mathrm{Mes} 2} \mathrm{H}$ and $\left[\mathrm{Cu}(\mathrm{NCMe})_{4}\right] \mathrm{PF}_{6}$ in THF showing the presence of free $\mathrm{TIB}^{\mathrm{Mes} 2} \mathrm{H}$.

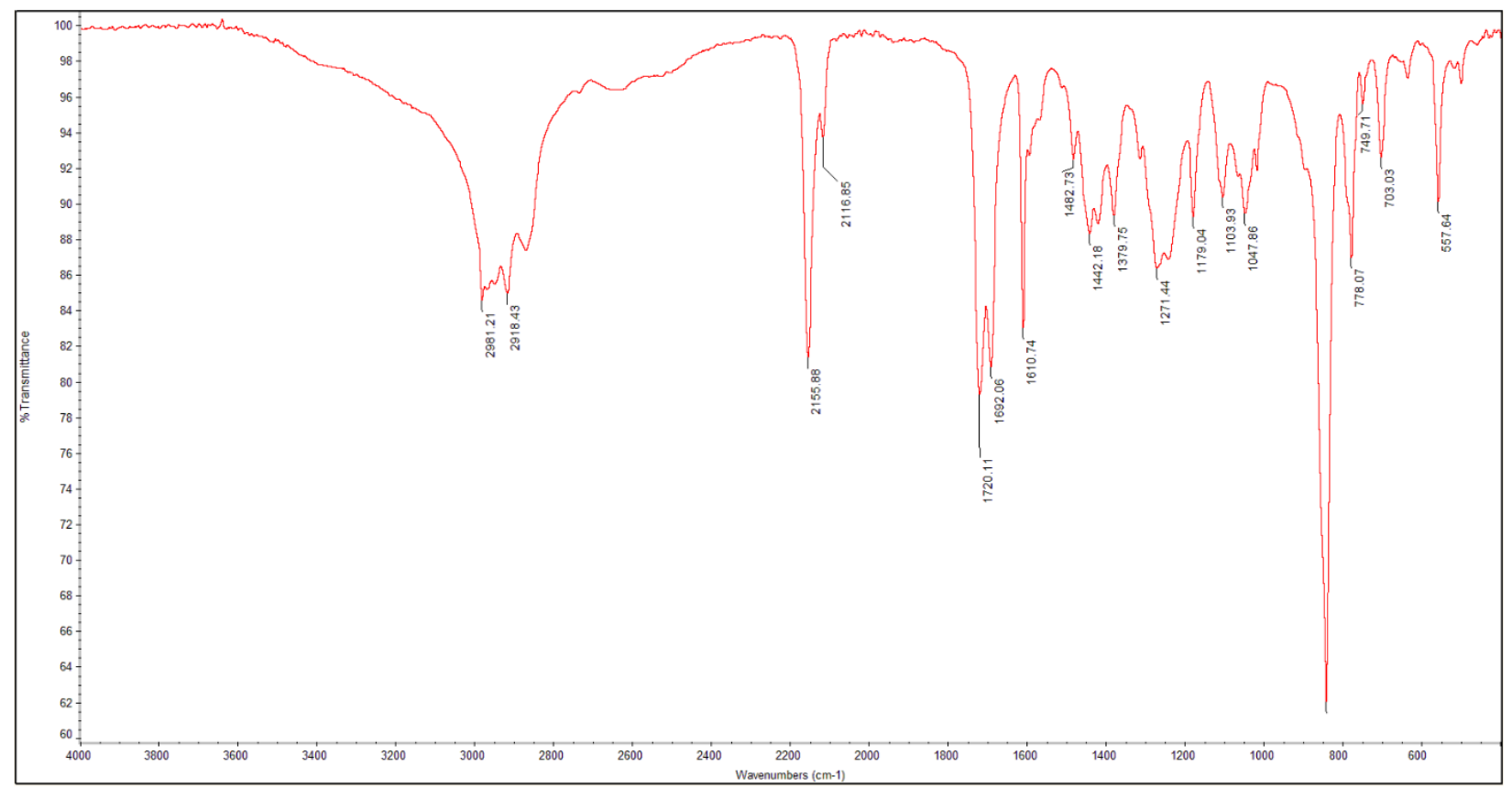

Figure S2.6. Solid State ATR-IR spectrum of 4.0 equiv $\mathrm{TIB}^{\mathrm{Mes} 2} \mathrm{H}$ and $\left[\mathrm{Cu}(\mathrm{NCMe})_{4}\right] \mathrm{PF}_{6}$ showing presence of free $\mathrm{TIB}^{\mathrm{Mes} 2} \mathrm{H}$. 


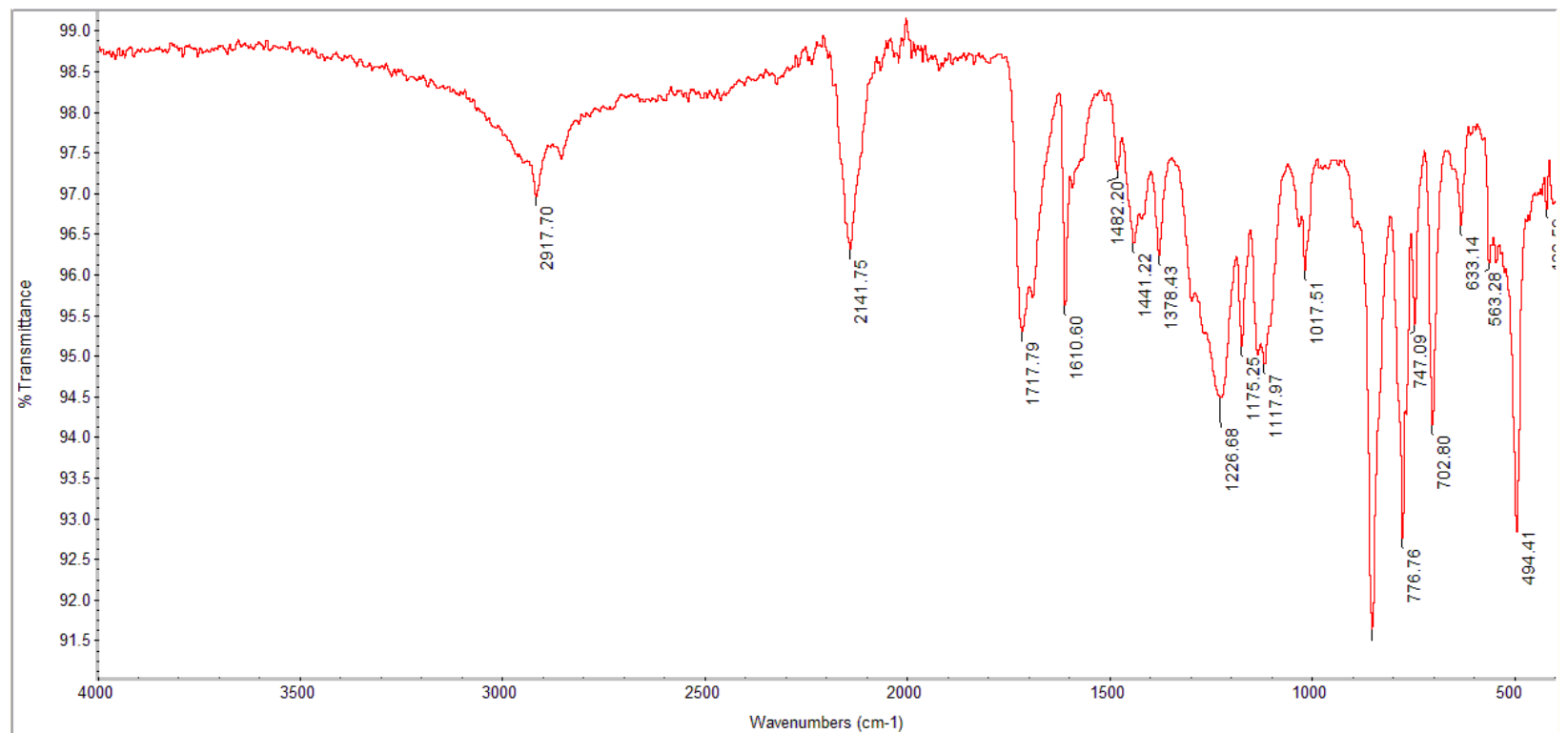

Figure S2.7. Solid State ATR-IR spectrum of the single-crystalline hydrogen-bonding network $\left[\mathrm{Cu}\left(\mathrm{TIB}^{\mathrm{Mes} 2} \mathrm{H}\right)_{4}\right] \mathrm{PF}_{6}$. Note that free $\mathrm{TIB}^{\mathrm{Mes} 2} \mathrm{H}$ is not present.

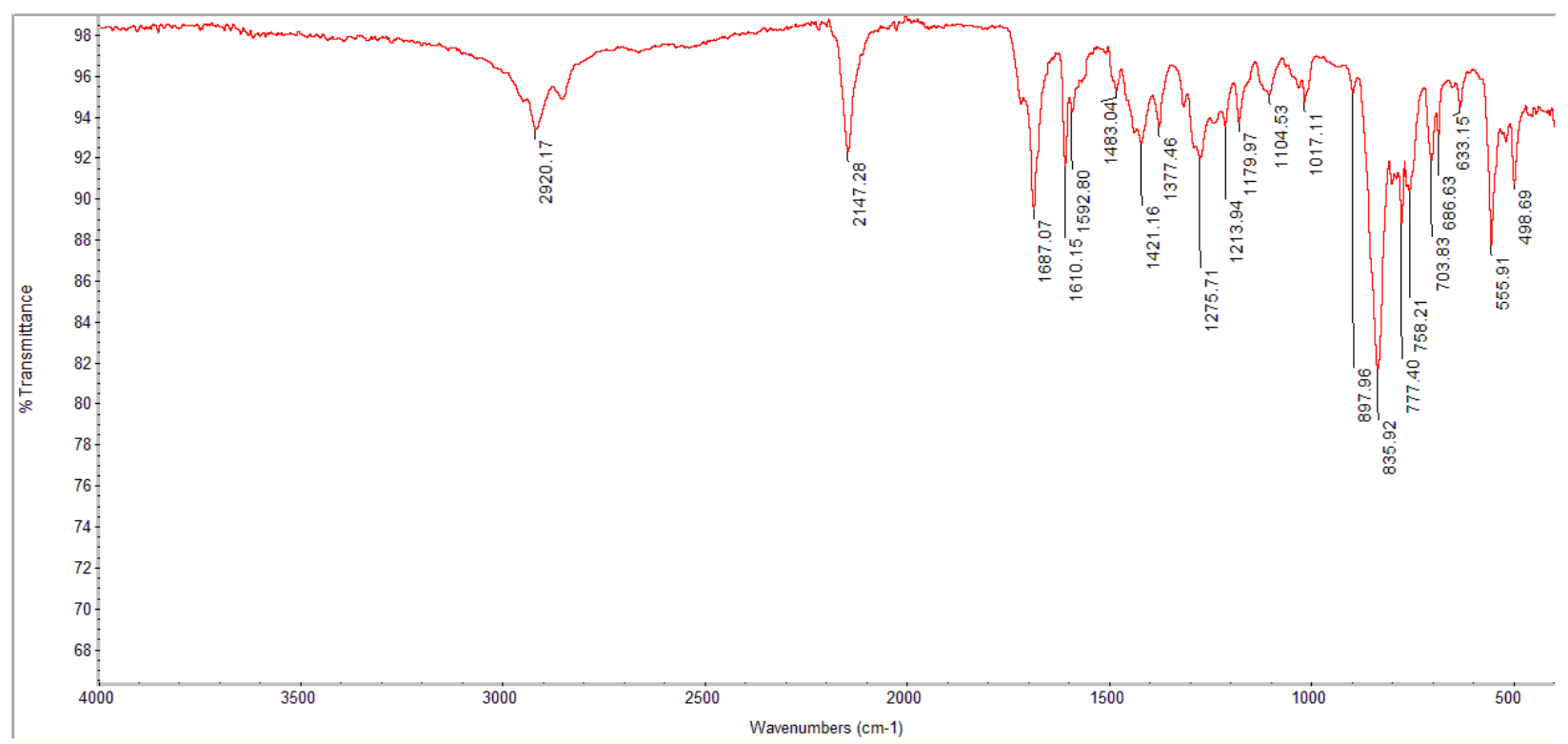

Figure S2.8. ATR-IR spectrum of single-crystalline $\left[\mathrm{Cu}\left(\mathrm{TIB}^{\mathrm{Mes} 2} \mathrm{H}\right)_{4}\right] \mathrm{PF}_{6}$ after exposure to deionized water for $24 \mathrm{~h}$. 


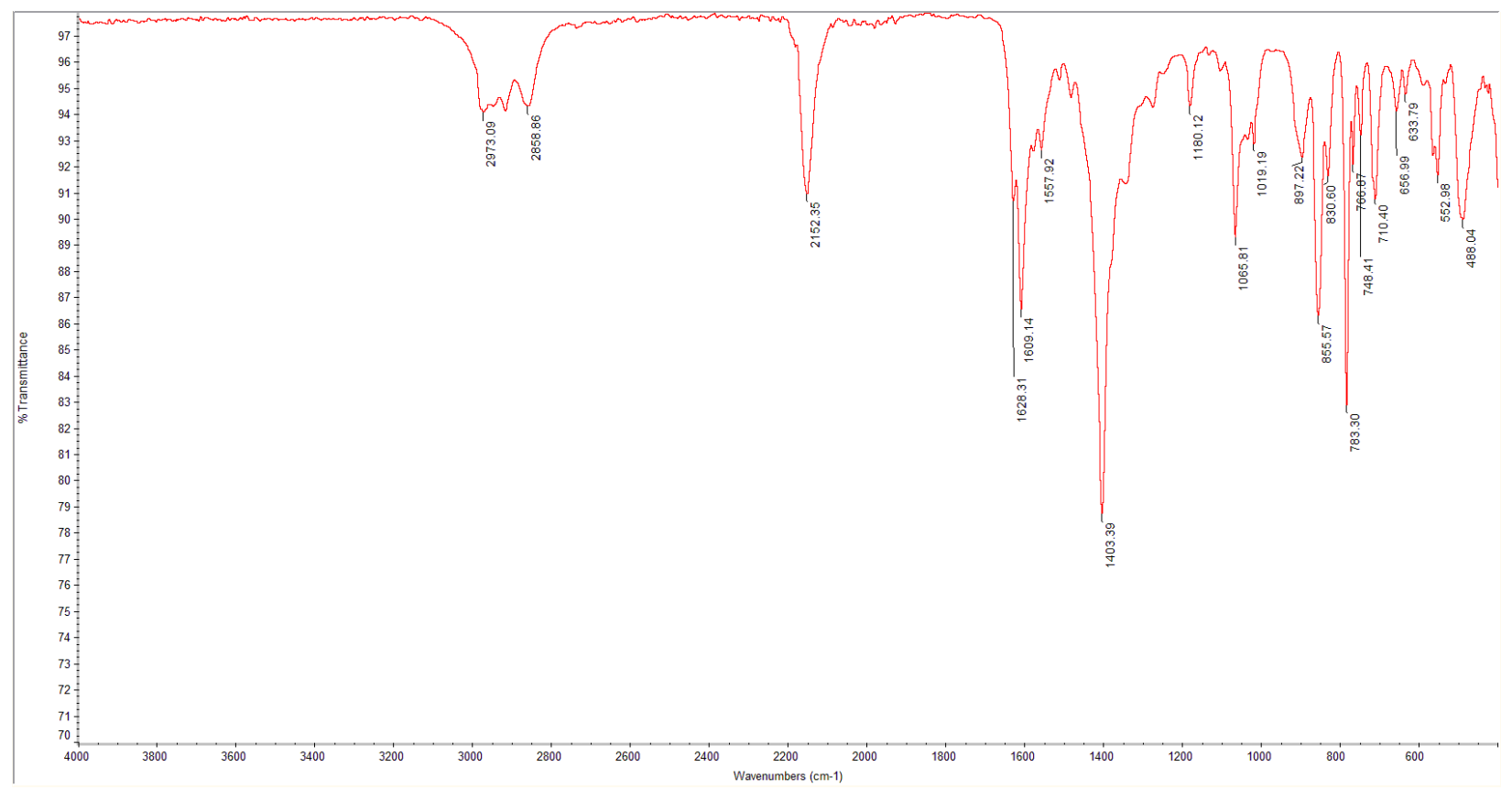

Figure S2.9. ATR-IR spectrum of $\mathrm{Cu} / \mathrm{Zn}-{ }^{\mathrm{ISO}} \mathrm{CN}-5$ using 3.0 equiv of $\mathrm{TIB}^{\mathrm{Mes} 2} \mathrm{H}$.

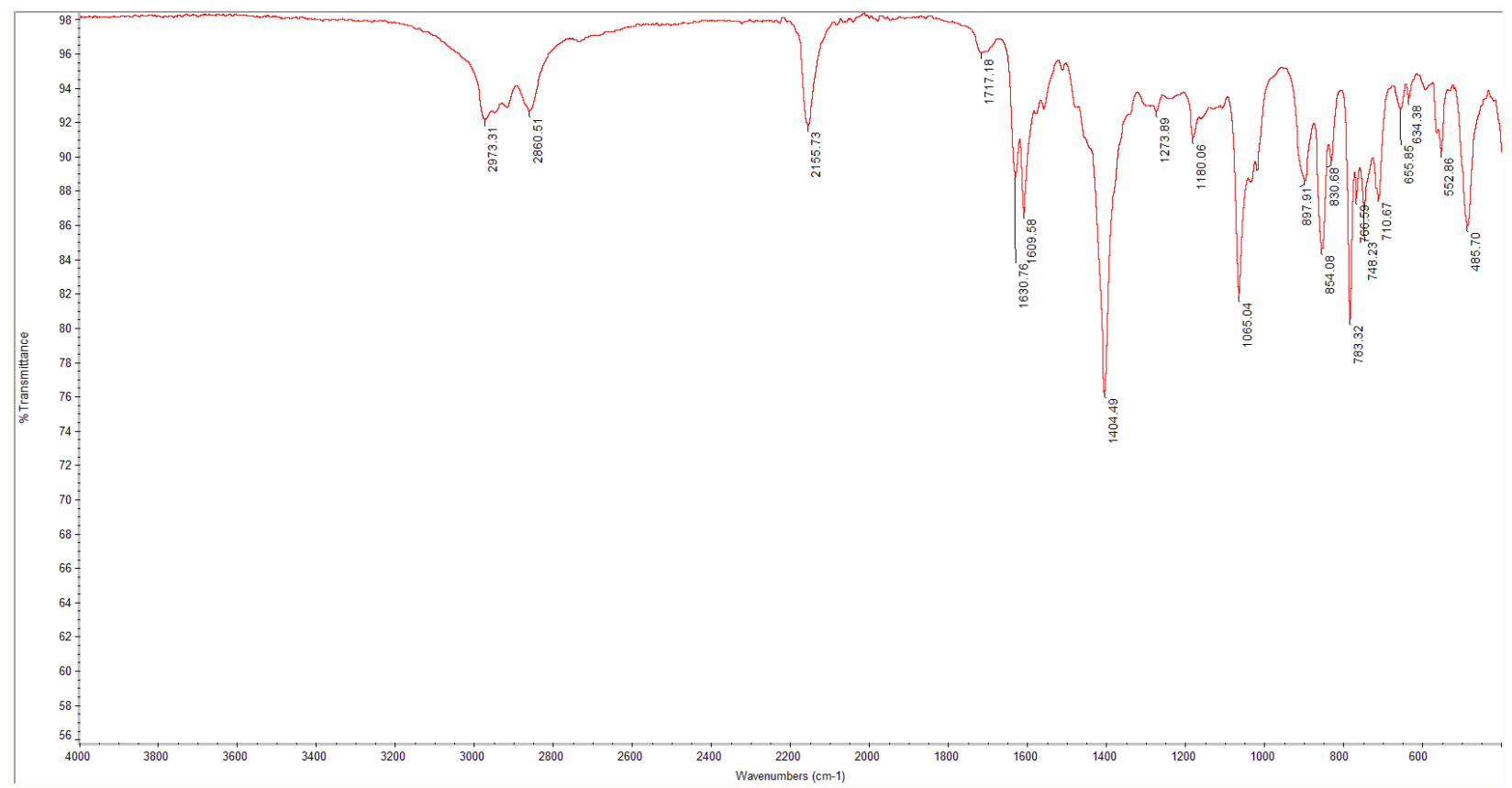

Figure S2.10. ATR-IR spectra of single-crystalline $\mathrm{Cu} / \mathrm{Zn}-\mathrm{Cu}-{ }^{\mathrm{ISO}} \mathrm{CN}-5$ using 4.0 equiv of $\mathrm{TIB}^{\mathrm{Mes} 2} \mathrm{H}$. 


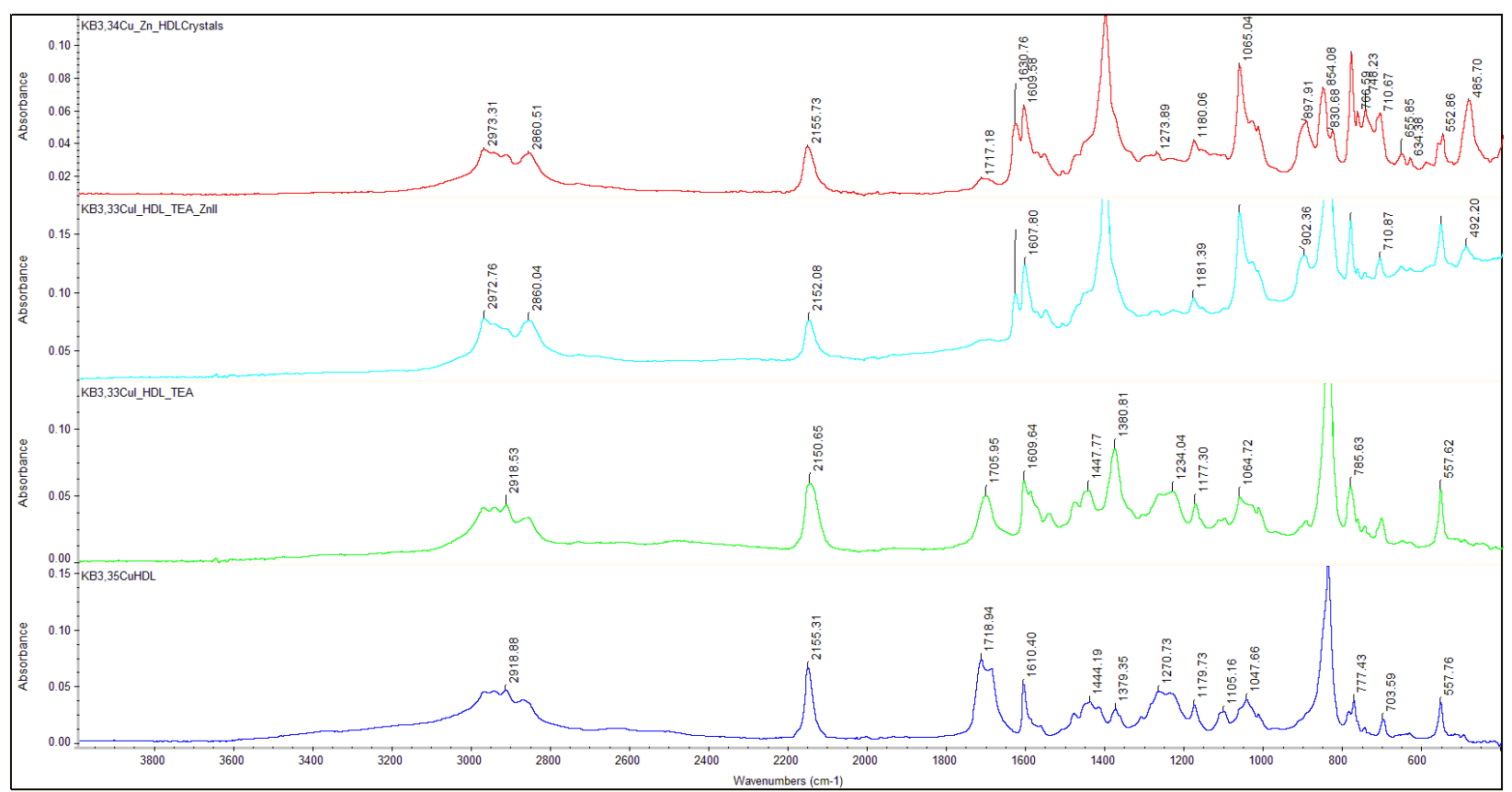

Figure S2.11. Stacked ATR-IR spectra of step-wise synthesis of $\mathrm{Cu} / \mathrm{Zn}^{\mathrm{ISO}} \mathrm{CN}-5$ employing 3.0 equivalents of $\mathrm{TIB}^{\mathrm{Mes} 2} \mathrm{H}$. (dark blue, bottom) initial formation of 3:1 $\mathrm{Cu}(\mathrm{I}) / \mathrm{TIB}^{\mathrm{Mes} 2} \mathrm{H}$ complex. (green) Deprotonation of 3:1 $\mathrm{Cu}(\mathrm{I}) / \mathrm{TIB}^{\mathrm{Mes} 2} \mathrm{H}$ complex with $\mathrm{NEt}_{3}$. (light blue) After addition of $\mathrm{ZnCl}_{2}$ prior to heating. (red, top) $\mathrm{Cu} / \mathrm{Zn}-{ }^{\mathrm{ISO}} \mathrm{CN}-5$ after solvothermal heating/cooling cycles. All spectra represent aliquots taken from the same sample.

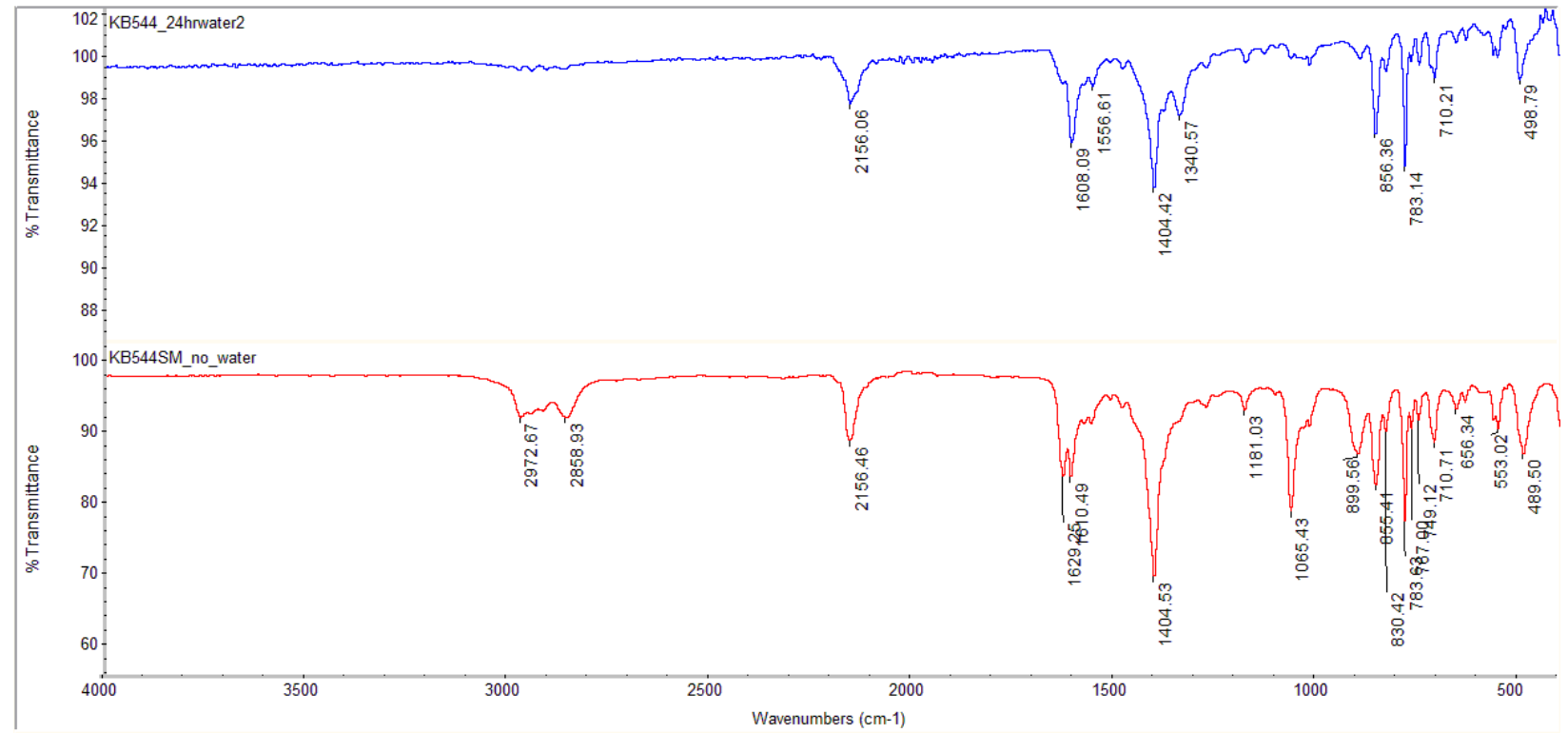

Figure S2.12. ATR-IR spectra of single-crystalline $\mathrm{Cu} / \mathrm{Zn}-{ }^{\mathrm{ISO}} \mathrm{CN}-5$ before (bottom) and after (top) exposure to deionized water for $24 \mathrm{~h}$. Note that spectra changes are apparent in carboxylate $v_{\mathrm{CO}}$ stretching region. 


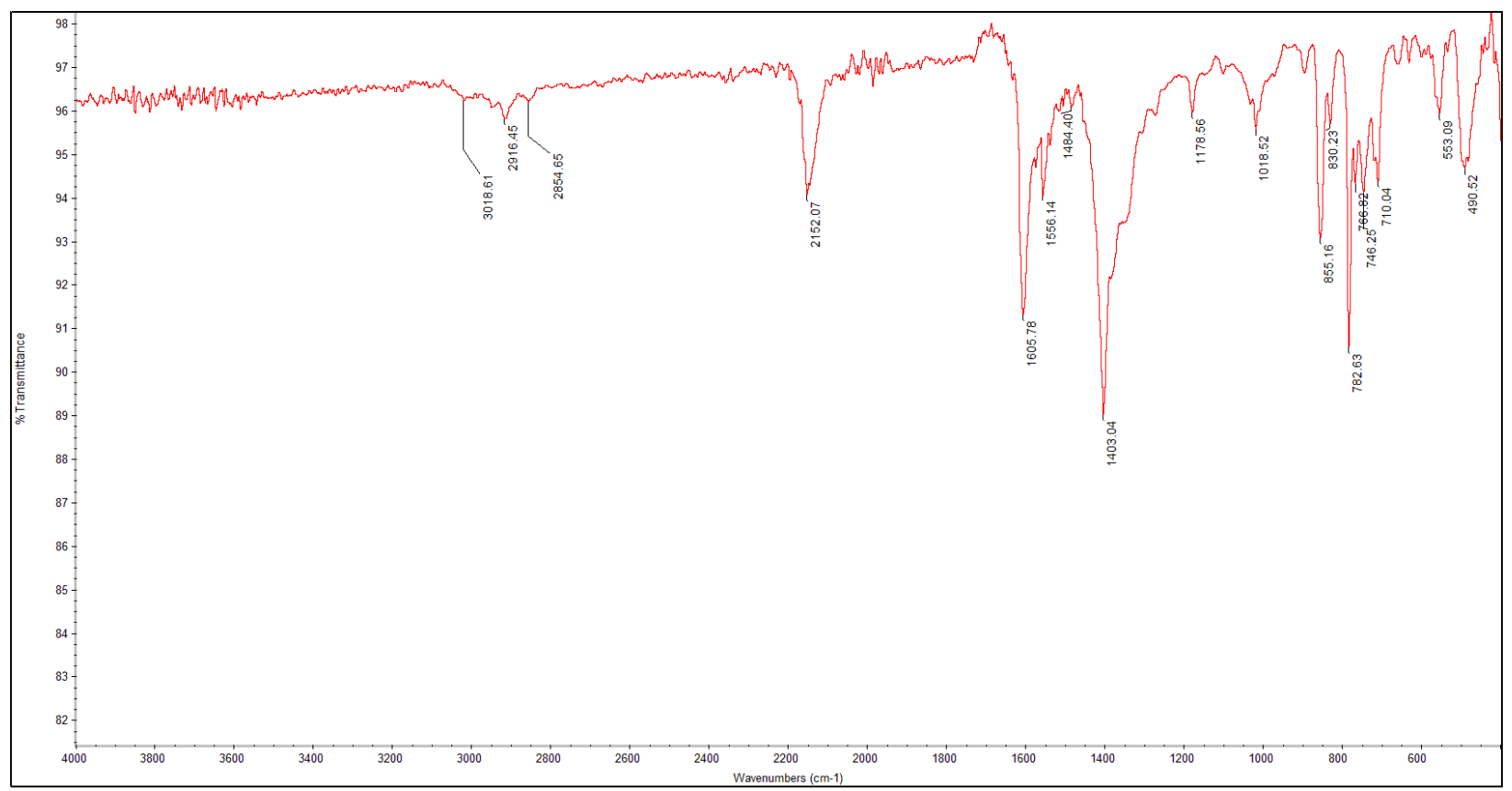

Figure S2.13. ATR-IR spectrum of $\mathrm{Cu} / \mathrm{Zn}-{ }^{\mathrm{ISO}} \mathrm{CN}-5$ after exposure to air for $20 \mathrm{~d}$.

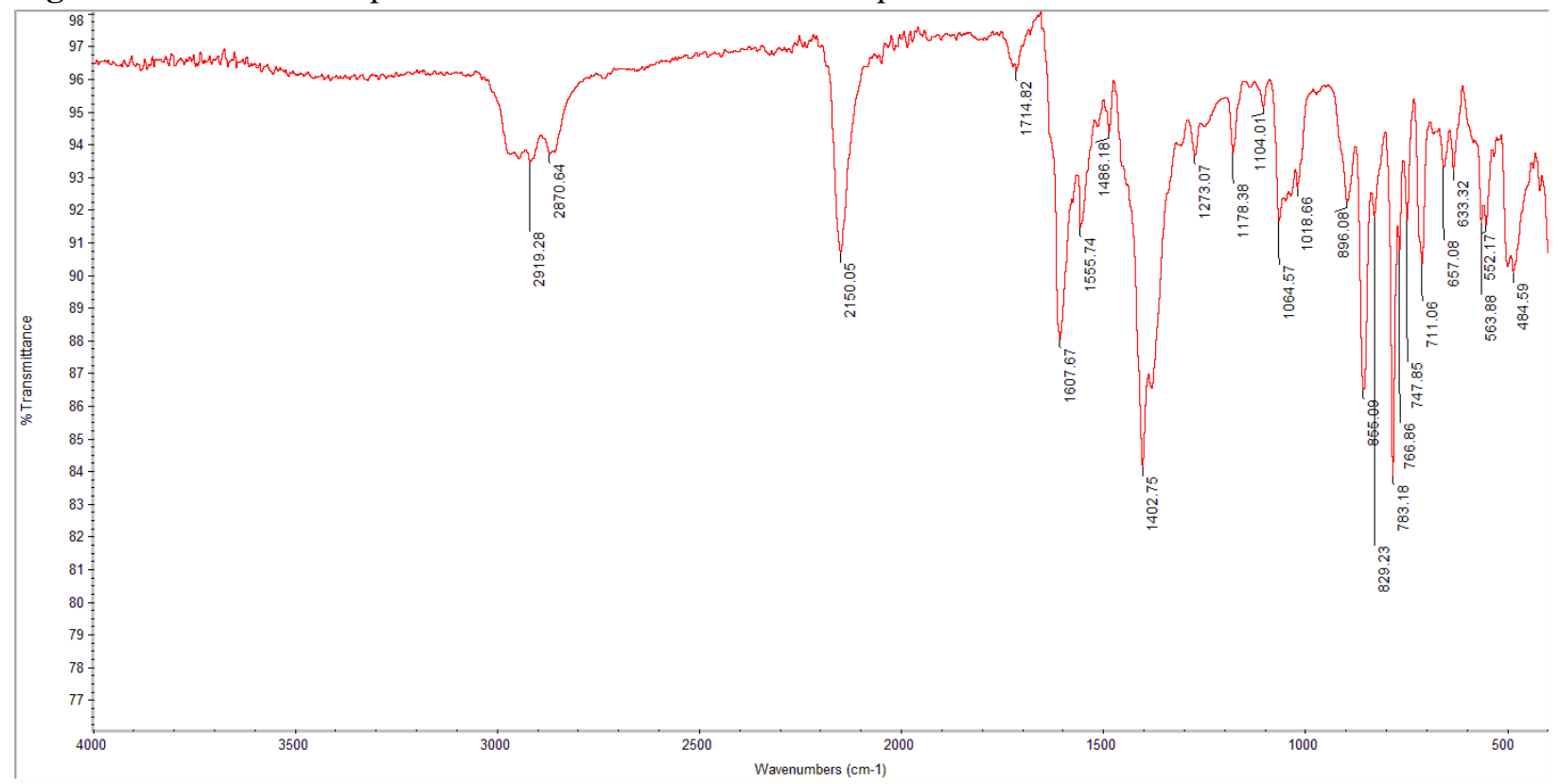

Figure S2.14. ATR-IR spectrum of $\mathrm{Cu} / \mathrm{Zn}-{ }^{\mathrm{ISO}} \mathrm{CN}-5$ after exposure to $1 \mathrm{~atm} \mathrm{O}_{2}$ for 24 hours.

\section{S.3. Results of ICP-MS Analysis on Digested Cu/Zn-ISO $\mathrm{CN}-5$.}

S3.1. General Inductively Coupled Plasma-Mass Spectrometry measurements were carried out on a single Quadrupole Thermo iCAP RQ ICP-MS. A sample of $\mathrm{Cu} / \mathrm{Zn}-{ }^{\mathrm{ISO}} \mathrm{CN}-5$ was washed three times with dry THF, dried in vacuo and dissolved in commercially available trace metal $\mathrm{HNO}_{3}(67-69 \%)$ from Fisher. The sample was then filtered and diluted to $100 \mathrm{ppb}$ of $\mathrm{Cu}$ metal in $10 \mathrm{~mL}$ of a solution containing $1 \% \mathrm{HNO}_{3}$ in 
MilliQ water. 4 x $10 \mathrm{~mL}$ calibration solutions containing 1ppb, $10 \mathrm{ppb}, 100 \mathrm{ppb}, 1000 \mathrm{ppb}$ of $\mathrm{Cu}$ and $\mathrm{Zn}$ respectively were prepared using a solution containing $1 \% \mathrm{HNO}_{3}$ in MilliQ water. These calibration solutions were prepared with the ICP-MS Complete Standard reagent (3\% v/v $\left.\mathrm{HNO}_{3}\right)$ purchased from Inorganic Ventures containing various metals including $10 \mu \mathrm{g} / \mathrm{mL} \mathrm{Cu}$ and $\mathrm{Zn}$. $50 \mu \mathrm{L}$ of the commercially available Internal Standard from Inorganic Ventures were added to all calibration solutions in addition to the sample solution prepared. A $10 \mathrm{~mL}$ blank solution was also prepared containing $1 \% \mathrm{HNO}_{3}$ in MilliQ water and the internal standard. All sample centrifuge tubes were cleaned beforehand by soaking in $2 \%$ $\mathrm{HNO}_{3}(\mathrm{aq})$ overnight, then rinsed with ultrapure MilliQ water.

Table S3. 1: ICP-MS results from digested sample of $\mathrm{Cu}-{ }^{\mathrm{ISO}} \mathrm{CN}-5$.

\begin{tabular}{|c|c|c|}
\hline & ${ }^{63} \mathbf{C u}[\mathrm{ppb}]$ & ${ }^{66 Z n ~[p p b]}$ \\
\hline Mean & 88.46742115 & 196.6146102 \\
\hline $\begin{array}{c}\text { Relative Standard } \\
\text { Deviation [\%] }\end{array}$ & 2.298029562 & 1.129497718 \\
\hline Standard Deviation & 2.033007491 & 2.220757534 \\
\hline
\end{tabular}

\section{S.4. TGA and Gas Sorption Analysis}

S4.1. Thermal Analysis. Thermogravimetric analysis was performed on $\sim 5-15 \mathrm{mg}$ of material that had been dried under dynamic vacuum for 30 minutes. Analysis was conducted under a stream of dry dinitrogen gas $(80 \mathrm{~mL} / \mathrm{min})$ using a Mettler Toledo TGA/DSC 1 STARe System running from $30{ }^{\circ} \mathrm{C}$ to $800{ }^{\circ} \mathrm{C}$ with a ramping rate of $5^{\circ} \mathrm{C} / \mathrm{min}$.

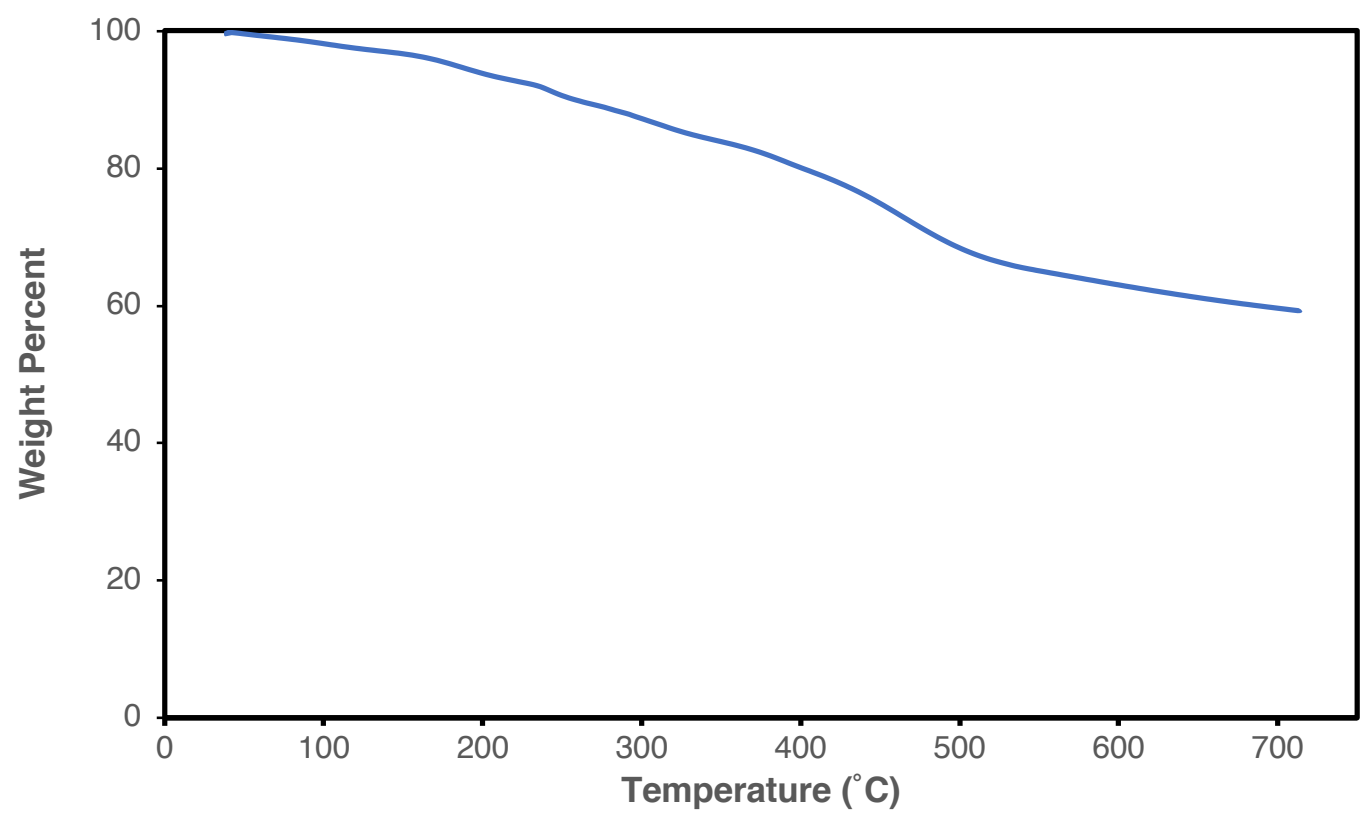

Figure S4.1. Thermogravimetric Analysis of $\left[\mathrm{Cu}\left(\mathrm{TIB}^{\mathrm{Mes} 2} \mathrm{H}\right)_{4}\right] \mathrm{PF}_{6}$ indicating a multi-step mass loss as a function of temperature. 


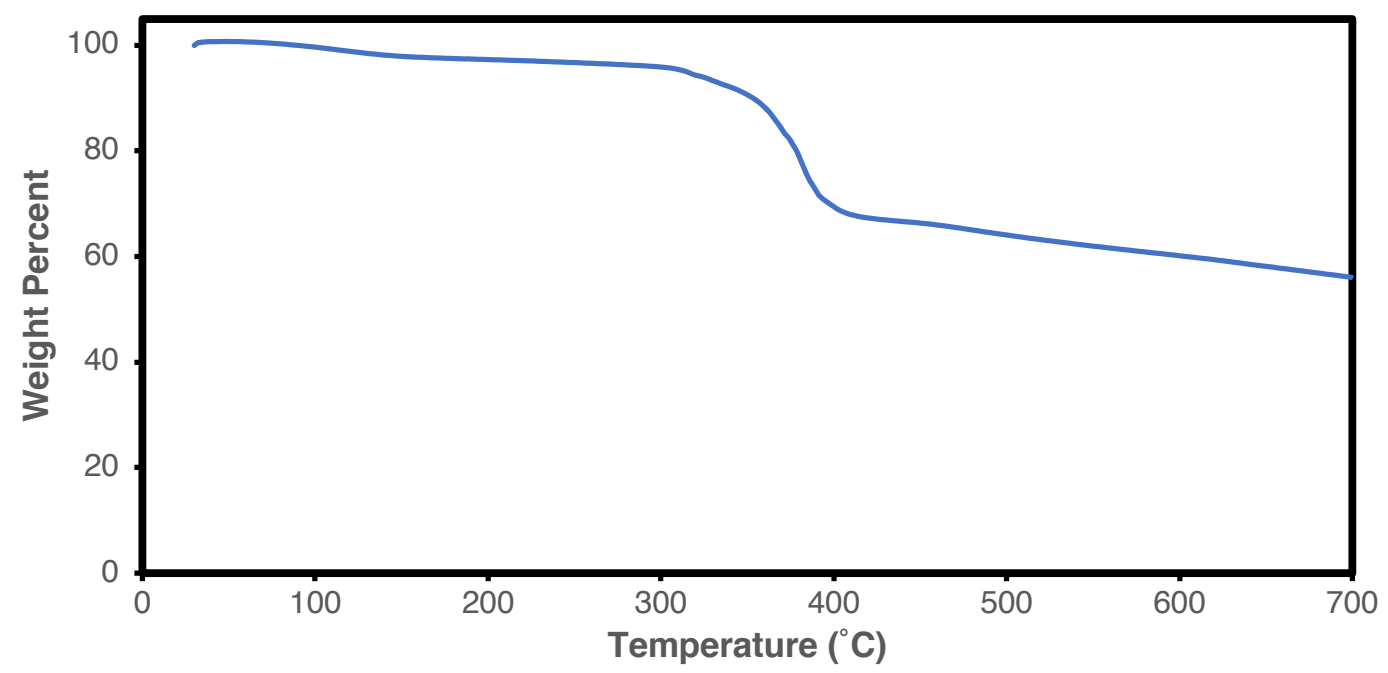

Figure S4.2. Thermogravimetric Analysis of $\mathrm{Cu} / \mathrm{Zn}-{ }^{\mathrm{ISO}} \mathrm{CN}-5$. Significant mass loss occurred at the onset temperature of $\sim 310^{\circ} \mathrm{C}$.

S4.2. Gas Sorption and Surface Area Analysis. Gas sorption measurements were performed using a Micrometrics ASAP 2020 Adsorption Analyzer. Approximately $54 \mathrm{mg}$ of material was transferred to a preweighed sample tube and degassed at $80{ }^{\circ} \mathrm{C}$ for at least 24 hours or until the outgas rate was below $5 \mathrm{mmHg}$. The sample tube was reweighed to obtain a mass for the sample. Analyses performed on $\mathrm{Cu} / \mathrm{Zn}-{ }^{\mathrm{ISO}} \mathrm{CN}-5$ degassed at $80{ }^{\circ} \mathrm{C}$ revealed insignificant surface areas in response to $\mathrm{N}_{2}$ sorption, but showed marginally greater sorption and surface area in the case $\mathrm{CO}_{2}$. 


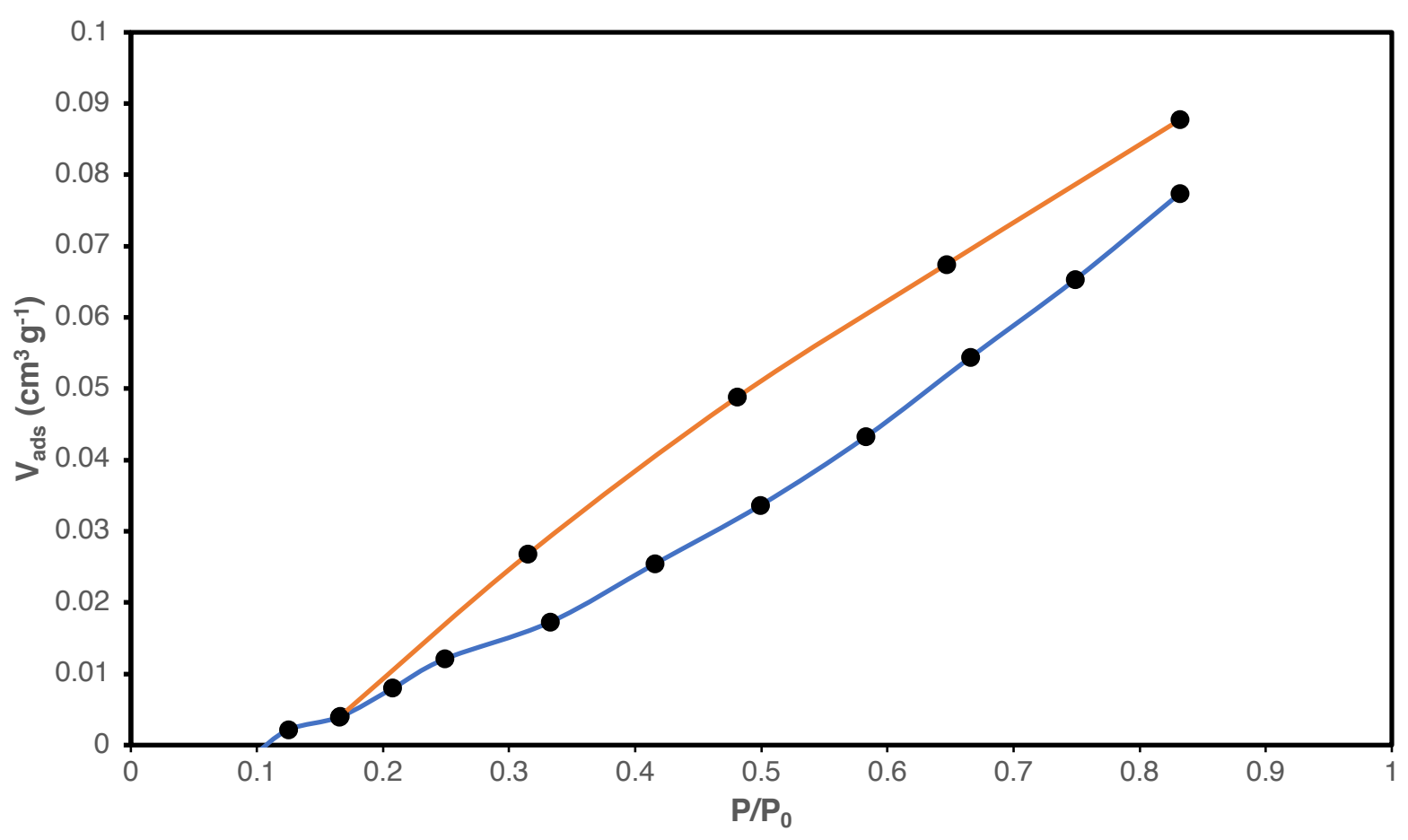

Figure S4.3. $\mathrm{N}_{2}$ sorption isotherm of activated $\mathrm{Cu}^{-}{ }^{\mathrm{SO}} \mathrm{CN}-5$ showing negligible gas uptake; blue= adsorption, orange $=$ desorption.

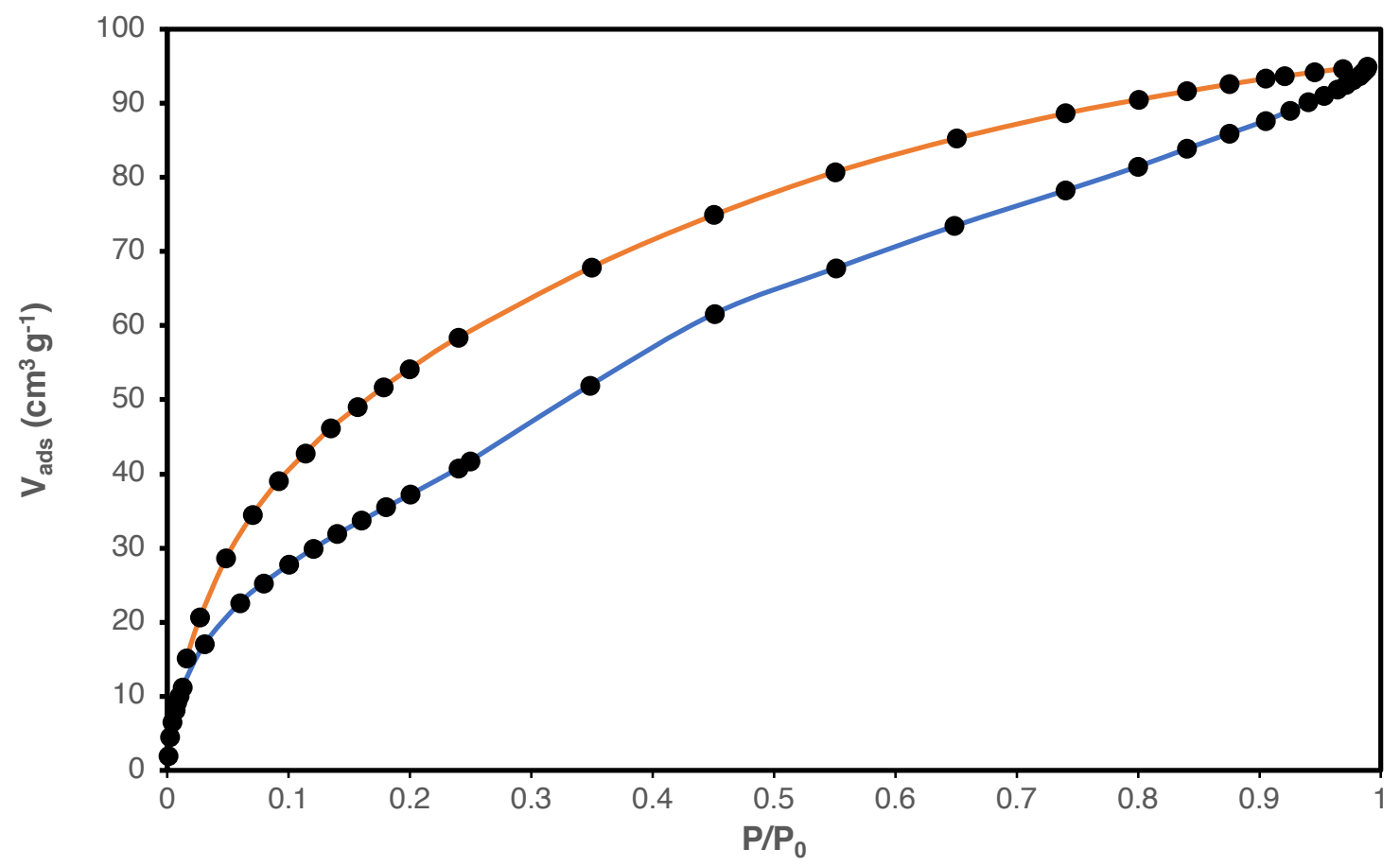

Figure S4.4. First run of $\mathrm{CO}_{2}$ sorption isotherm of activated $\mathrm{Cu}-{ }^{\mathrm{ISO}} \mathrm{CN}-5$; blue $=$ adsorption, orange $=$ desorption. 


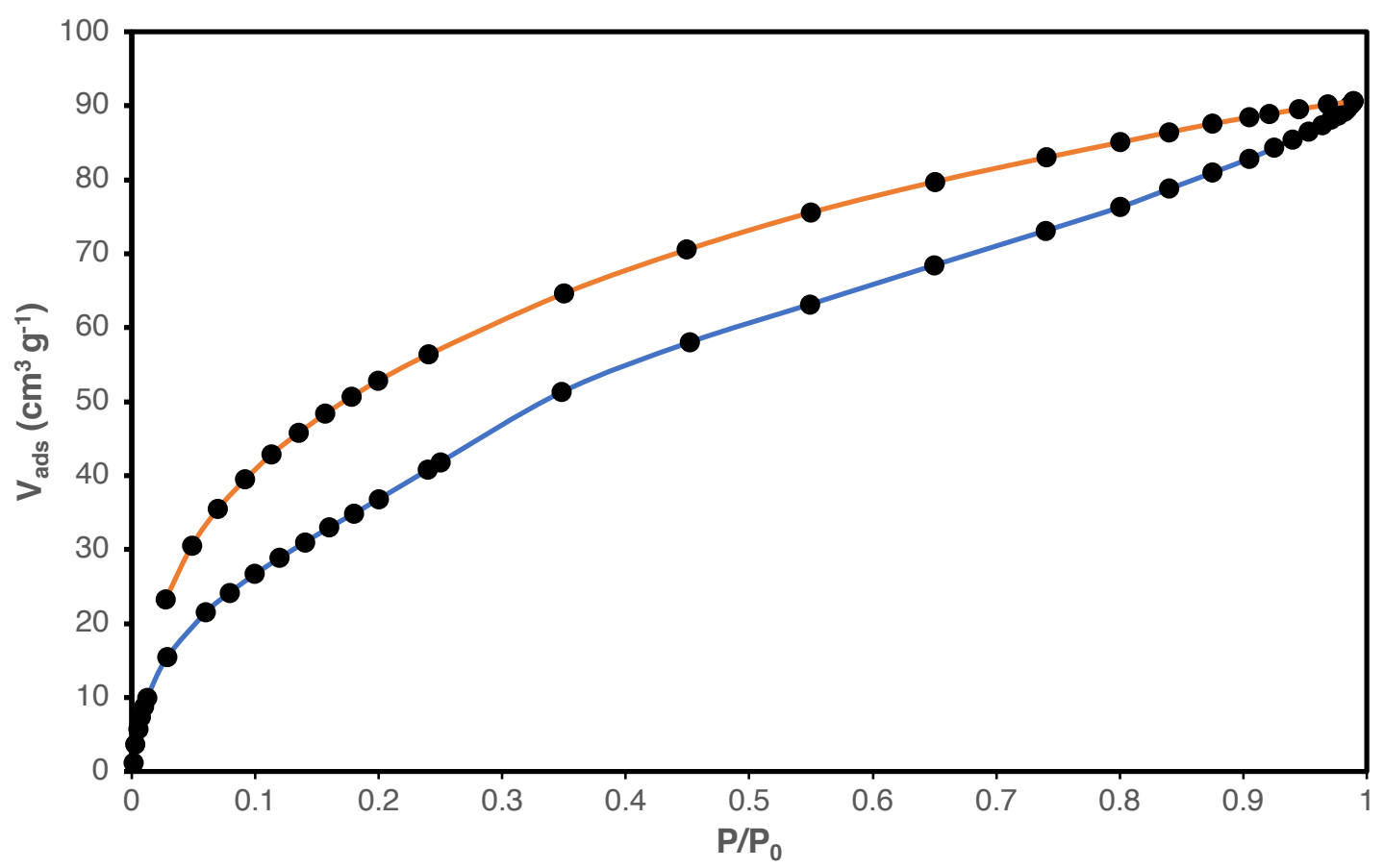

Figure S4.5 Second independent run of $\mathrm{CO}_{2}$ sorption isotherm of activated $\mathrm{Cu}-{ }^{\mathrm{ISO}} \mathrm{CN}-5$; blue $=$ adsorption, orange $=$ desorption.

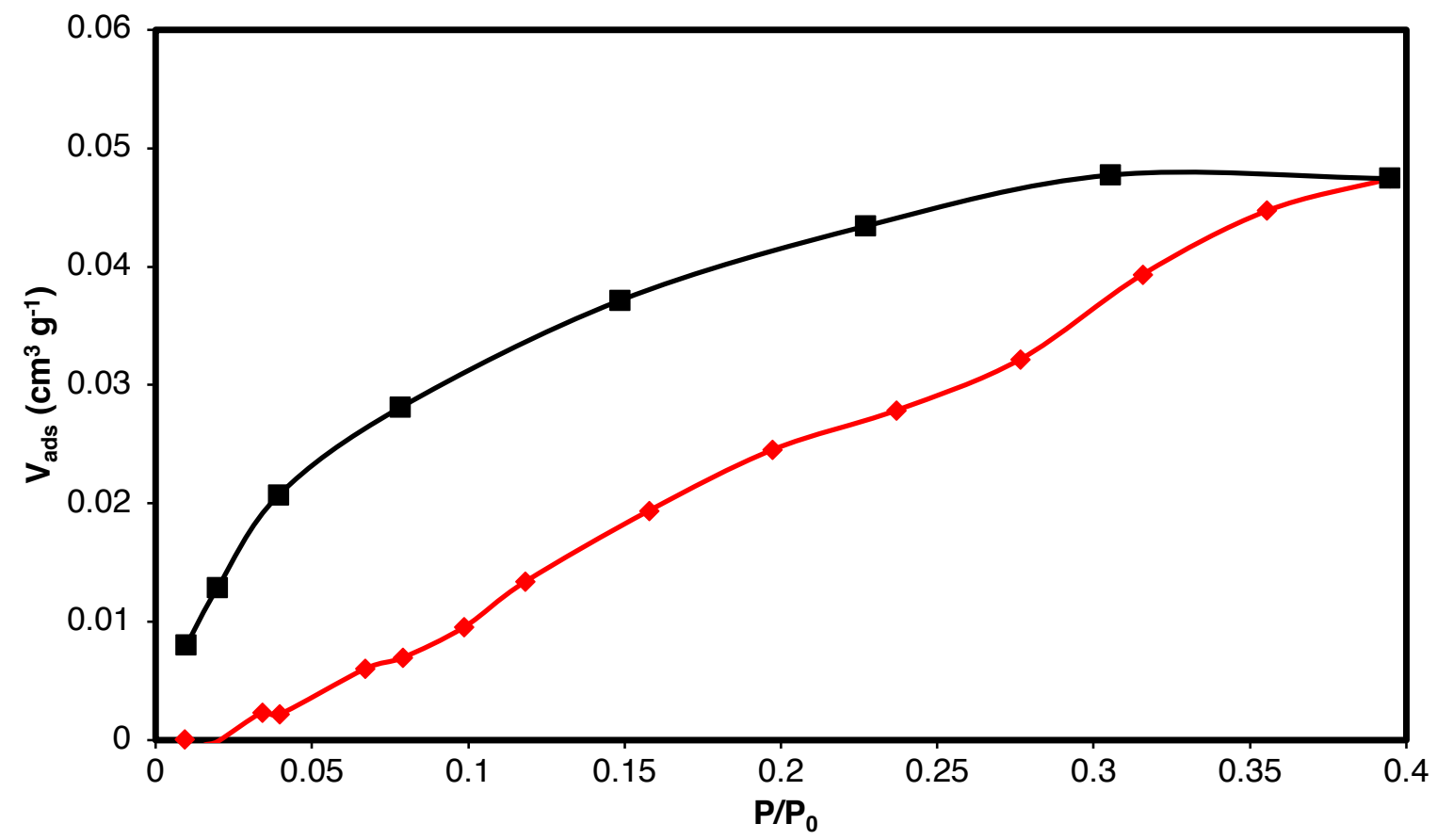

Figure S4.6. $\mathrm{O}_{2}$ sorption isotherm of activated $\mathrm{Cu}-{ }^{\mathrm{ISO}} \mathrm{CN}-5$, showing negligible gas uptake; red = adsorption, black $=$ desorption. 


\section{S.5. Results of X-ray Single-Crystal and Powder Diffraction Studies}

S5.1. General. Single crystal X-ray structure determinations were carried out at low temperature on Platform Diffractometers equipped with either $\mathrm{Cu} \mathrm{K} \alpha$ radiation sources and Bruker APEX II detectors. All structures were solved by direct methods with SHELXS ${ }^{1-2}$ and refined by full-matrix least-squares procedures utilizing SHELXL within Olex2 small-molecule solution, refinement, and analysis software package. ${ }^{3}$ Crystallographic data collection and refinement information are listed in Table S5.1. Powder Xray diffraction studies on $\mathrm{Cu} / \mathrm{Zn}-{ }^{\mathrm{ISO}} \mathrm{CN}-5$ were performed at room temperature on a Bruker D8 Advanced LynxEye CCD diffractometer, equipped with $\mathrm{Cu} \mathrm{K \alpha}$ radiation $(\lambda=1.54178 \AA)$ and $\mathrm{K} \beta$ filter. Diffraction measurements were set to $40 \mathrm{~V}$ and $40 \mathrm{~mA}$.

\section{S5.2. Details of Single-Crystal Refinement.}

S5.2.2. $\left[\mathbf{C u}\left(\mathbf{T I B}^{\mathrm{Mes} 2} \mathbf{H}\right)_{4}\right] \mathbf{P F}_{6}$. The $\left[\mathrm{PF}_{6}\right]^{-}$counterion is located on a special position in the $P 4_{2} / n$ space group, which results in significant positional disorder. Due to the fact that $0.25\left[\mathrm{PF}_{6}\right]^{-}$units are present in the asymmetric unit, the anion was modeled with hard SADI and RIGU restraints on the P-F bonds to account for the disorder. This structure was also found to contain disordered, sub-stoichiometric molecules of $\mathrm{CH}_{2} \mathrm{Cl}_{2}$ of co-crystallization which could not be modeled as discrete entities. To account for the disorder, the residual electron density fitted and refined as floating $\mathrm{Cl}$ and $\mathrm{C}$ atoms, which gave better refinement statistics than structure factor elimination using the Platon/SQUEEZE procedure.

S5.2.2. $\mathrm{Cu}^{\text {ISO }} \mathrm{CN}-5$. The benzoate unit one $\mathrm{TIB}^{\mathrm{Mes} 2}$ linker possesses positional disorder, which was modeled and refined anisotropically. Significant positional disorder was also observed for THF molecules of cocrystallization and could not be reasonably modeled. These were treated with Platon/SQUEEZE to remove structure factors/electron density prior to refinement.

Table S5. 1: Crystallographic data collection and refinement information.

\begin{tabular}{|c|c|c|c|}
\hline Name & $\begin{array}{c}1,4- \\
\left(\mathrm{CNAr}^{\mathrm{Mes} 2}\right) \mathrm{C}_{6} \mathrm{H}_{4} \mathrm{CO}_{2} \mathrm{H} \\
\left(\mathrm{TIB}^{\mathrm{Mes} 2} \mathrm{H}\right)\end{array}$ & {$\left[\mathrm{Cu}(\mathrm{TIB})_{4}\right] \mathrm{PF}_{6}$} & $\mathrm{Cu} / \mathrm{Zn}-{ }^{\mathrm{ISO}} \mathrm{CN}-5$ \\
\hline Formula & $\mathrm{C}_{32} \mathrm{H}_{29} \mathrm{NO}_{2}$ & $\begin{array}{c}\mathrm{C}_{133.06} \mathrm{H}_{122.29} \mathrm{Cl}_{15.19} \mathrm{CuF}_{6} \\
\mathrm{~N}_{4} \mathrm{O}_{8} \mathrm{P}\end{array}$ & $\mathrm{C}_{96} \mathrm{H}_{84} \mathrm{Cl}_{2} \mathrm{CuN}_{3} \mathrm{O}_{6} \mathrm{Zn}_{2}$ \\
\hline Crystal System & Monoclinic & Tetragonal & Orthorhombic \\
\hline Space Group & $P 2 / c$ & $P 4_{2} / n$ & $F d d 2$ \\
\hline$a, \AA$ & $19.5157(7)$ & $16.4879(4)$ & 21.9954(7) \\
\hline$b, \AA$ & $8.0632(3)$ & $16.4879(4)$ & $27.7005(8)$ \\
\hline$c, \AA$ & $16.3195(6)$ & $26.0255(8)$ & 43.0962(11) \\
\hline$\alpha, \operatorname{deg}$ & 90 & 90 & 90 \\
\hline$\beta, \operatorname{deg}$ & $106.966(2)$ & 90 & 90 \\
\hline$\gamma, \operatorname{deg}$ & 90 & 90 & 90 \\
\hline $\mathrm{V}, \AA^{3}$ & $2456.25(16)$ & $7075.1(4)$ & $26257.8(13)$ \\
\hline$Z$ & 4 & 2 & 8 \\
\hline
\end{tabular}




$\begin{array}{cccc}\text { Radiation }(\lambda, \AA) & \mathrm{Cu}-\mathrm{K} \alpha, 1.54178 & \mathrm{Cu}-\mathrm{K} \alpha, 1.54178 & \mathrm{Cu}-\mathrm{K} \alpha, 1.54178 \\ \rho \text { (calcd.), } \mathrm{g} / \mathrm{cm}^{3} & 1.243 & 1.245 & 0.830 \\ \mu(\mathrm{Mo} \mathrm{Ka}), \mathrm{mm}^{-1} & 0.599 & 3.457 & 1.266 \\ \text { Temp, K } & 100 & 100 & 100 \\ \theta \text { max, deg } & 72.782 & 63.232 & 49.549 \\ \text { data/parameters } & 4670 / 0 / 324 & 5761 / 111 / 499 & 6487 / 17 / 514 \\ R_{l} & 0.0434(4339) & 0.0771 & 0.0506(5243) \\ w R_{2} & 0.1152(4887) & 0.2258 & 0.1372(6487) \\ \mathrm{GOF} & 1.080 & 1.075 & 1.001\end{array}$

S5.3. CCDC Deposition. All crystal structures have been deposited with the Cambridge Crystallographic Data Center (CCDC) and have been assigned the following CCDC deposition numbers:

- TIB $^{\text {Mes22 H: } 2085631}$

- $\left[\mathbf{C u}\left(\text { TIB }^{\text {Mes2 }}\right)_{4}\right]$ PF $_{6}: 2085632$

- $\mathrm{Cu} / \mathrm{Zn}-{ }^{\mathrm{ISO}} \mathrm{CN}-5: 2085633$

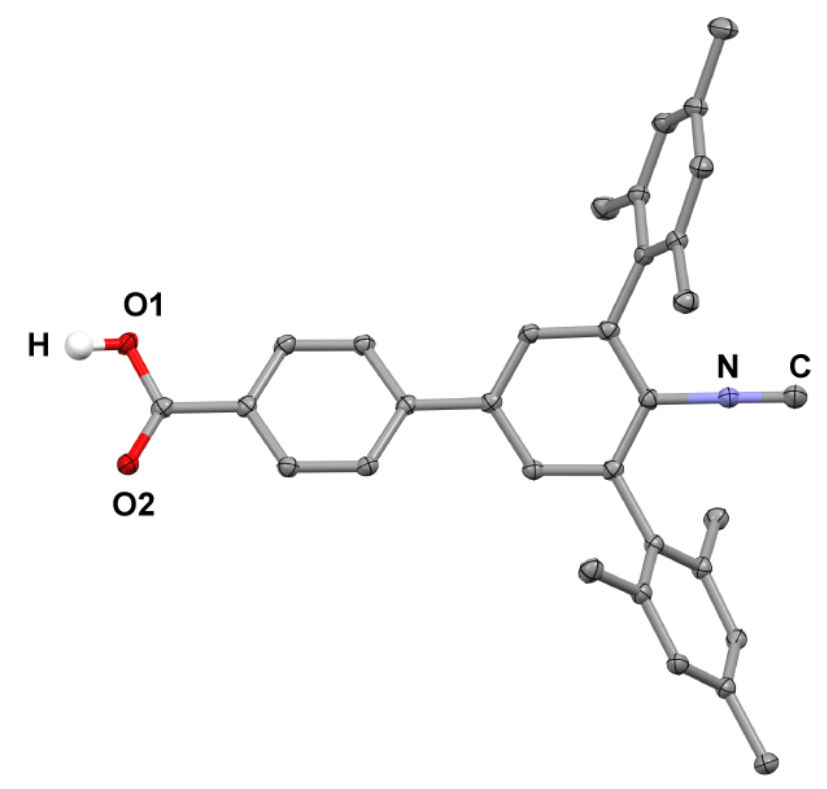

Figure S5.1. Molecular structure of $1,4-\left(\mathrm{CNAr}^{\mathrm{Mes} 2}\right) \mathrm{C}_{6} \mathrm{H}_{4} \mathrm{CO}_{2} \mathrm{H}\left(\mathrm{TIB}^{\mathrm{Mes} 2} \mathrm{H}\right)$. 

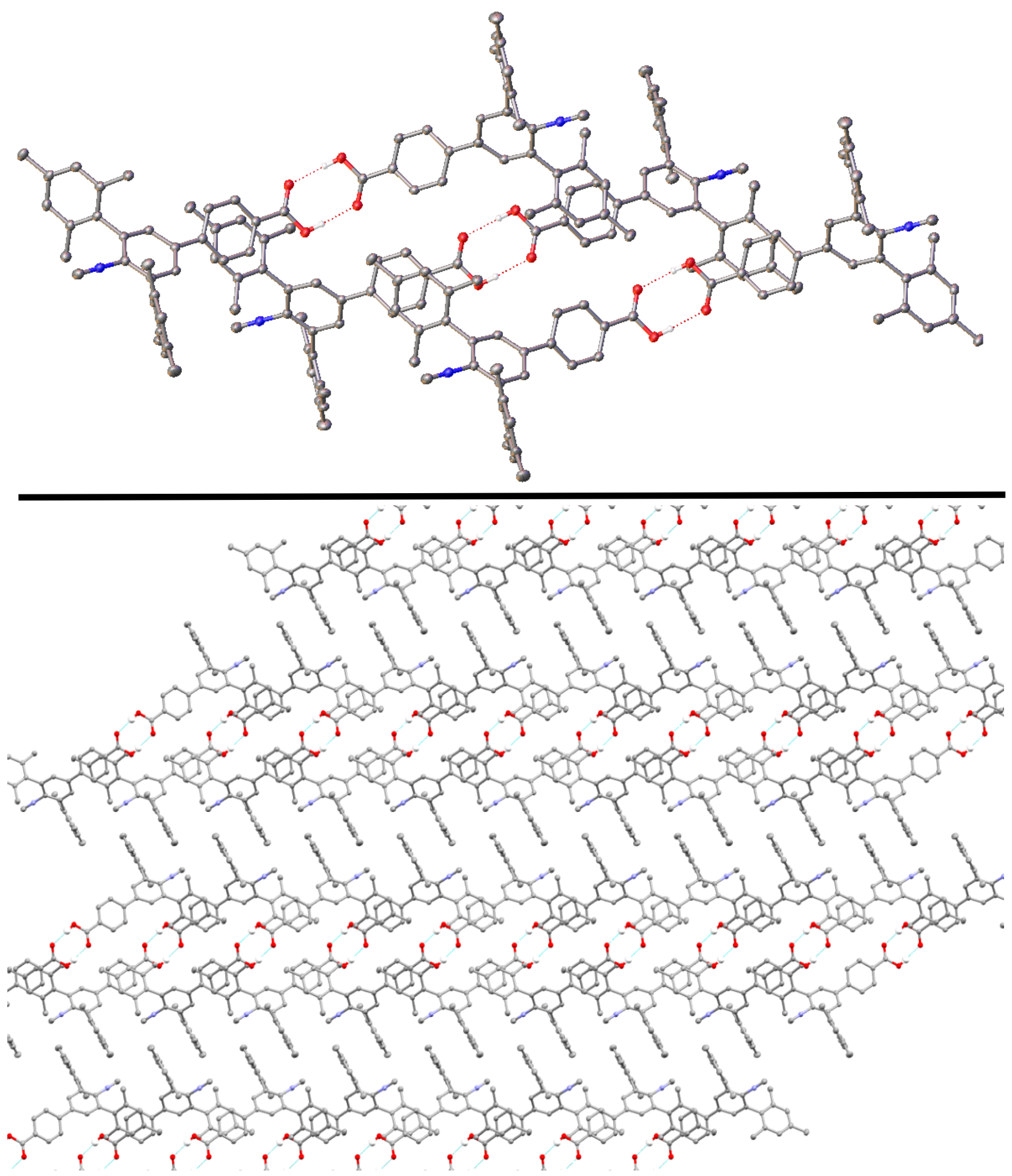

Figure S5.2. Packing Diagram for $1,4-\left(\mathrm{CNAr}^{\mathrm{Mes} 2}\right) \mathrm{C}_{6} \mathrm{H}_{4} \mathrm{CO}_{2} \mathrm{H}\left(\mathrm{TIB}^{\mathrm{Mes} 2} \mathrm{H}\right)$ showing intermolecular hydrogen bonding interactions (top). View down crystallographic $b$ axis (bottom) showing herringbone structure. 


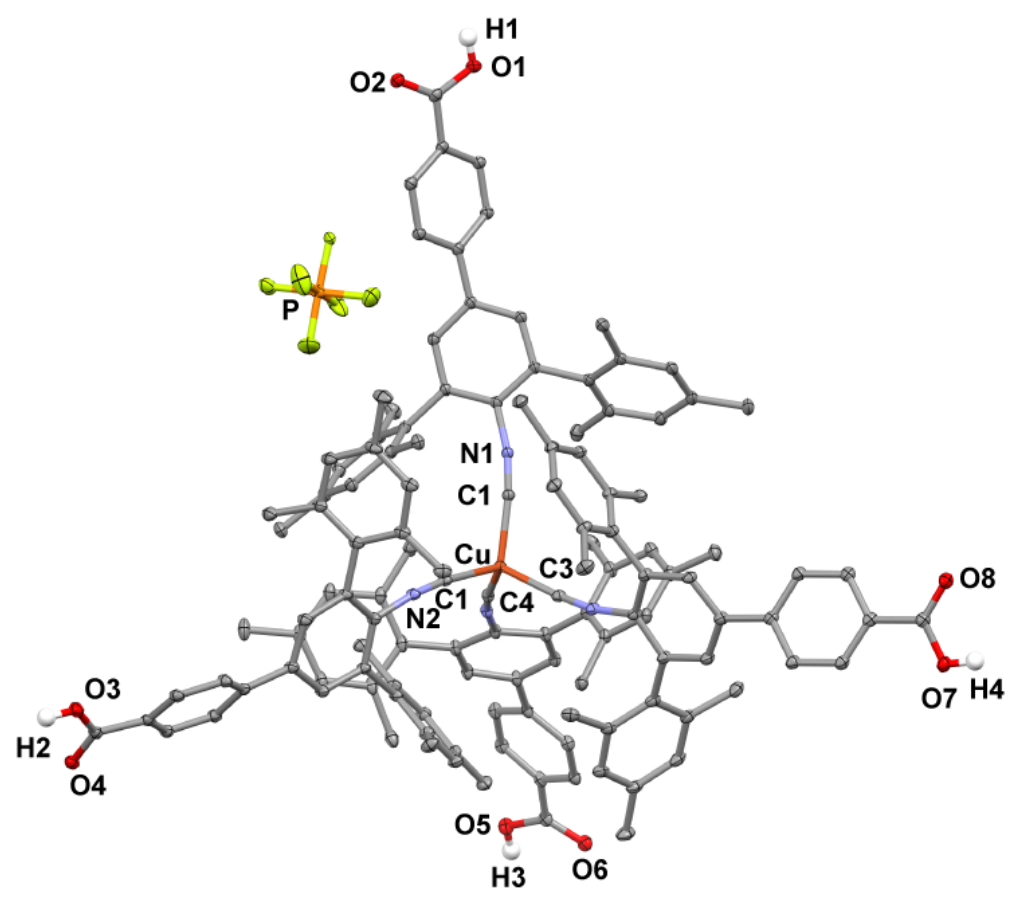

Figure S5.3. Structure of the Molecular Core for $\left[\mathrm{Cu}\left(\mathrm{TIB}^{\mathrm{Mes} 2} \mathrm{H}\right)_{4}\right] \mathrm{PF}_{6}$.

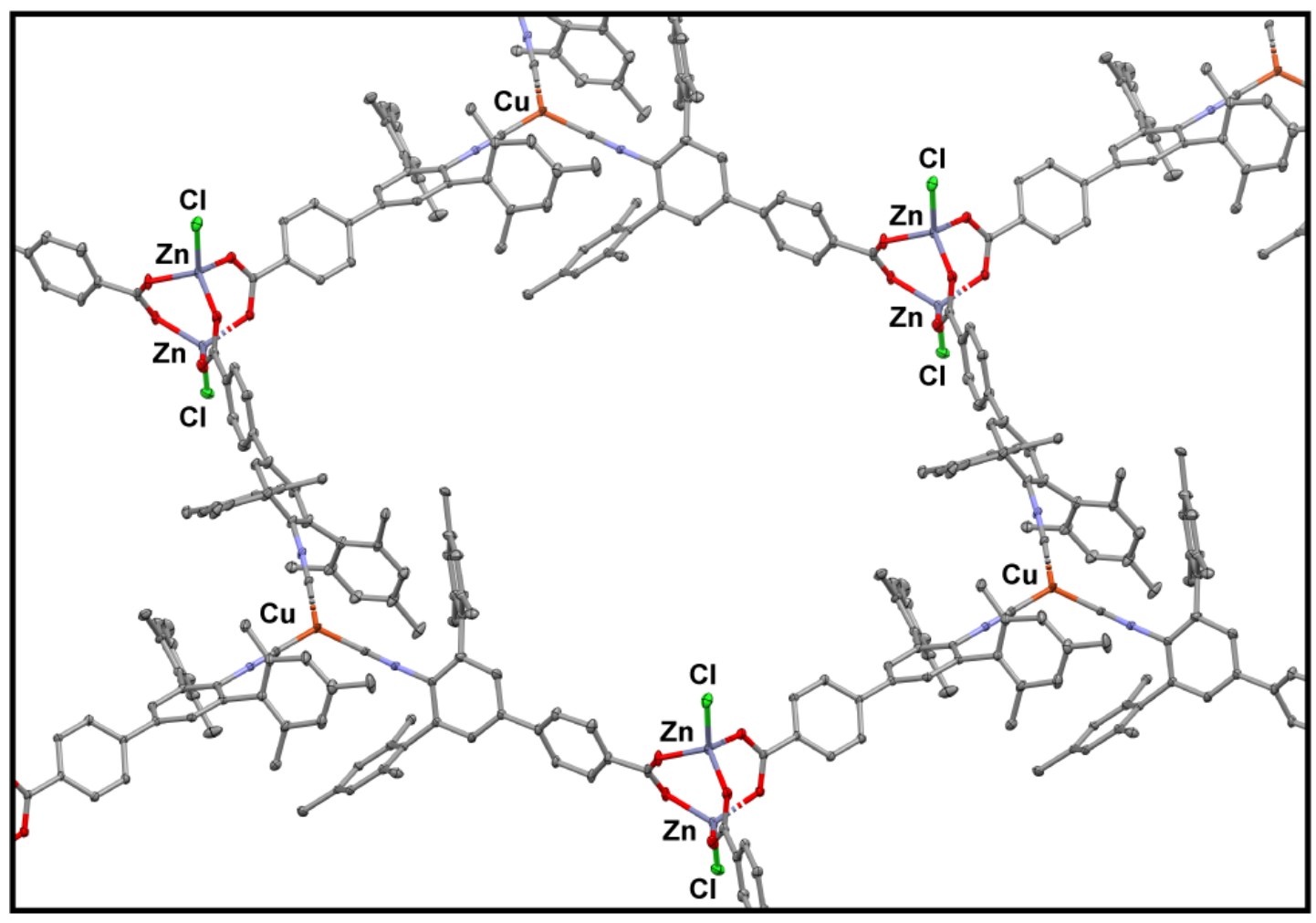

Figure S5.4. Structure Dual-SBU Repeat Unit in $\mathrm{Cu} / \mathrm{Zn}-{ }^{\mathrm{ISO}} \mathrm{CN}-5$ containing a tris-isocyanide $\mathrm{Cu}(\mathrm{I})$ core and $\mathrm{Zn}$ paddlewheel unit with axial $\mathrm{Cl}$ ligand. 


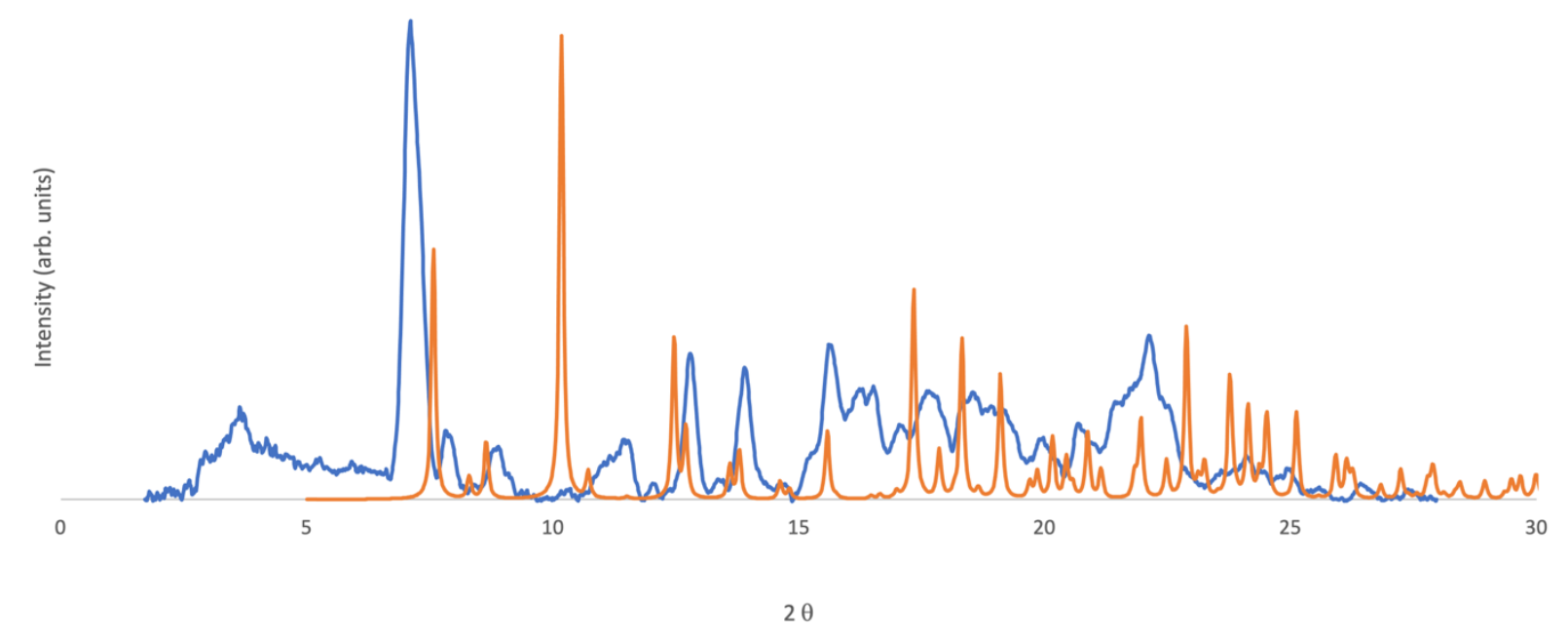

Figure S5.5. PXRD overlay of solid material obtained from the reaction between $\left[\mathrm{Cu}(\mathrm{NCMe})_{4}\right] \mathrm{PF}_{6}$ and 3.0 equiv of $\mathrm{TIB}^{\mathrm{Mes} 2} \mathrm{H}$ (blue trace) and simulated powder pattern from single-crystalline $\left[\mathrm{Cu}\left(\mathrm{TIB}^{\mathrm{Mes} 2} \mathrm{H}\right)_{4}\right] \mathrm{PF}_{6}$ (orange trace). The difference between the powder patterns indicates differing phases for these materials.

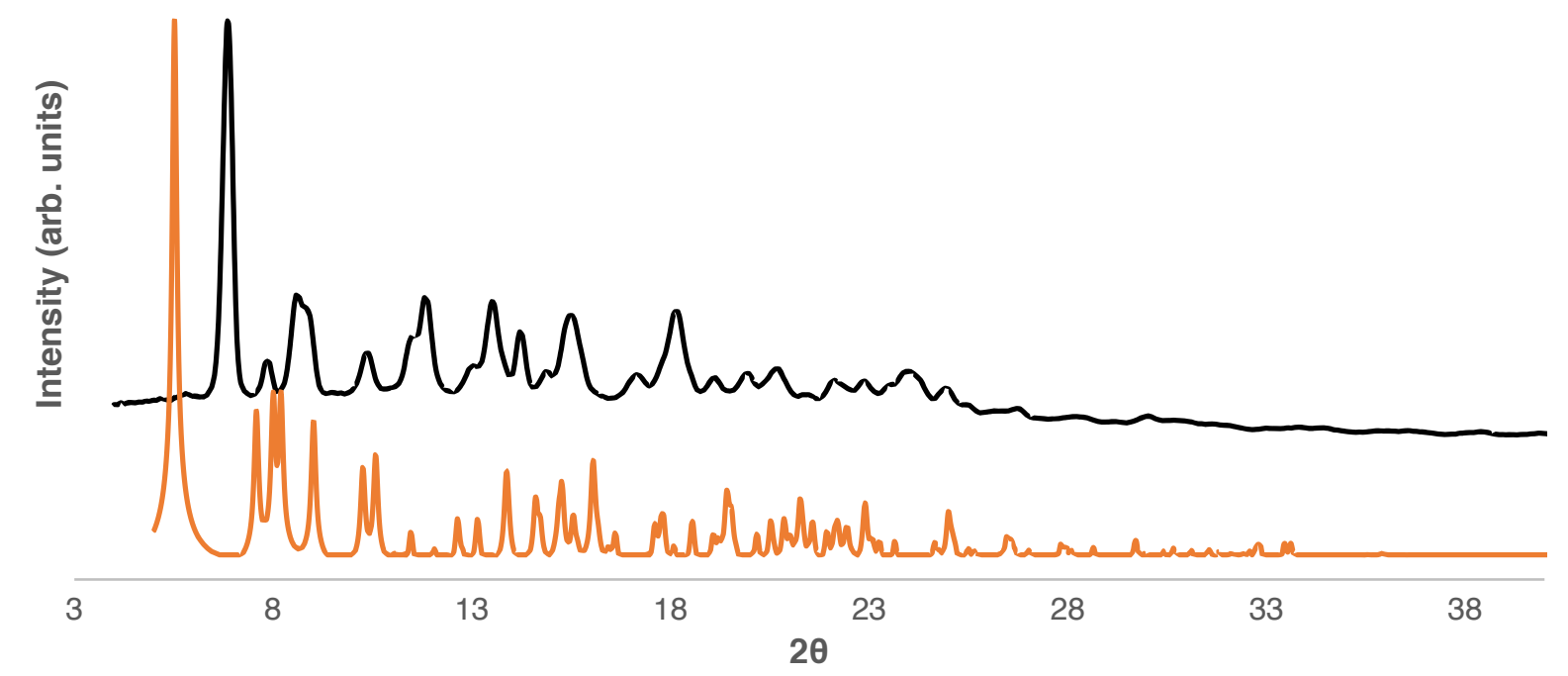

Figure S5.6. Powder X-ray Diffraction Pattern of $\mathrm{Cu} / \mathrm{Zn}-{ }^{\mathrm{ISO}} \mathrm{CN}-5$, experimental (black) and simulated from single crystal diffraction (orange). 


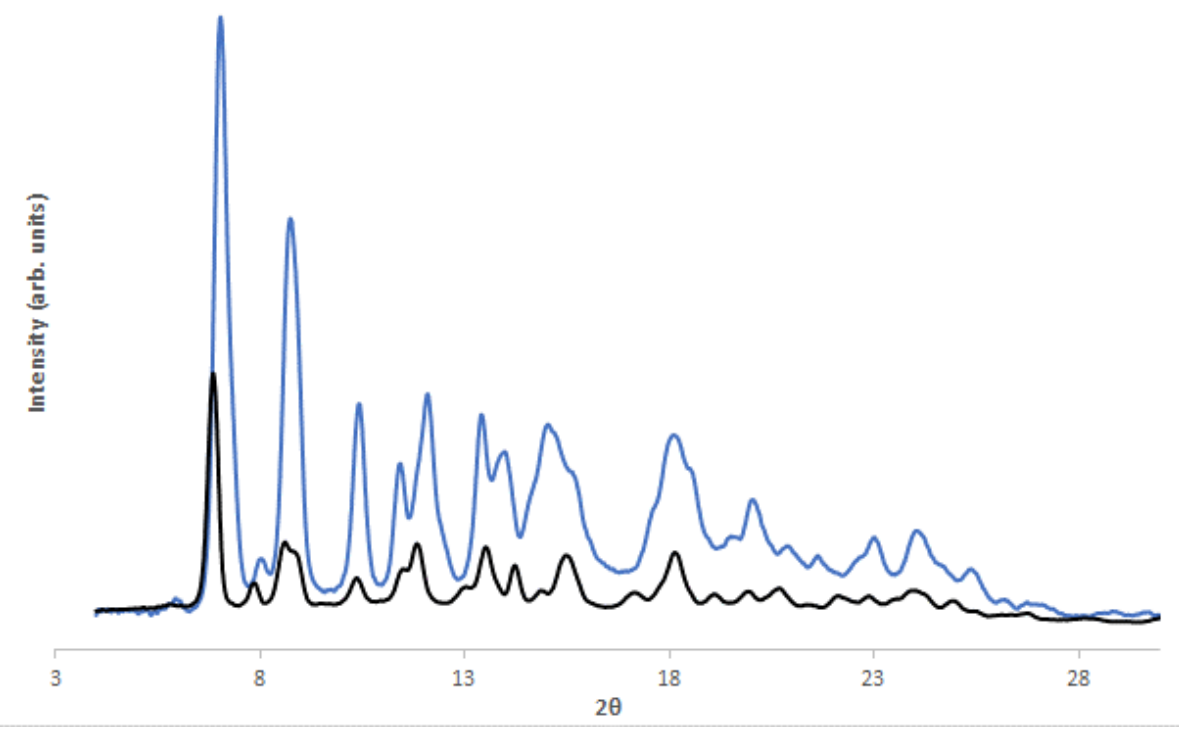

Figure S5.7. Powder X-ray diffraction pattern of Cu- ${ }^{\mathrm{ISO}} \mathrm{CN}-5$ as synthesized (black) and after exposure to air for 20 days (blue).

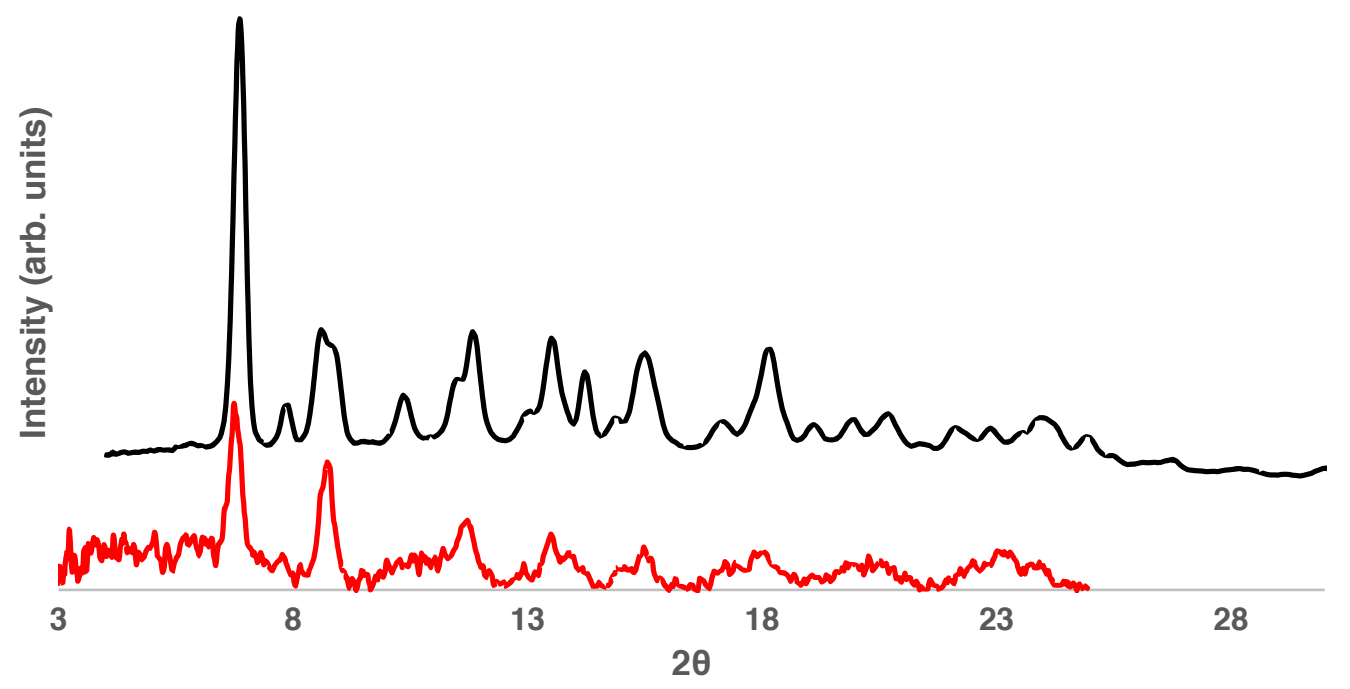

Figure S5.8. Powder X-ray diffraction pattern of $\mathrm{Cu}^{-}{ }^{\mathrm{ISO}} \mathrm{CN}-5$ as synthesized (black) and after suspension in water 24 for h (red). A loss of crystallinity is observed over the course of 24 hours. 


\section{S.6. References}

(1) Sheldrick, G., A short history of SHELX. Acta Crystallogr. Sec. A 2008, 64, 112-122.

(2) Sheldrick, G., Crystal structure refinement with SHELXL. A Acta Crystallogr. Sec. C 2015, 71 (1), 3-8.

(3) Dolomanov, O. V.; Bourhis, L. J.; Gildea, R. J.; Howard, J. A. K.; Puschmann, H., OLEX2: a complete structure solution, refinement and analysis program. J. Appl. Crystallogr. 2009, 42, 339341. 